\title{
Un pueblo es un lugar. La forma urbana de un pueblo de pastores ante las lógicas del Estado. Coranzulí, Puna de Jujuy, Argentina, del 1900 al hoy
}

\section{A town is a place. The urban form of a town of shepherds facing the logics of the State. Coranzulí, Puna de Jujuy, Argentina, from 1900 to the present}

\author{
Julieta Barada' 투
}

\begin{abstract}
RESUMEN
Los pueblos de pastores en los Andes, y en particular en la Argentina, han sido históricamente concebidos en la tensión entre las dinámicas de movilidad de la población, y los intereses estatales enfocados en la sedentarización de la misma, constituyéndose en nodos para proceso "civilizatorio" basado en el binomio rural-urbano. En este artículo analizaremos, a través de fuentes gráficas y escritas, el devenir de la forma urbana de Coranzulí, (Puna de Jujuy, Argentina) del 1900 a la actualidad, observando las acciones del Estado Argentino y, en particular, como los actores locales han ido negociando en y desde la forma urbana del pueblo sus propios intereses, desde los que es posible redefinir y maniobrar la propia lógica hegemónica del Estado. Es en este marco que propondremos que el pueblo se conforma como un lugar en cuya especificidad se reconocen modos de actuar relaciones más amplias, definidas dinámicamente.
\end{abstract}

Palabras clave: Area Andina, Urbanismo, Estado Nacional, Pastoreo.

\begin{abstract}
Shepherds villages in the Andes, and specifically in Argentina, have been historically conceived in the tension between mobility dynamics from local people and National State interests, focused in their settlement, being constituted as nodes for a "civilizing" process based on the rural-urban binomial. In this article, we will analyze, through graphic and written documents, the evolution of the urban form of Coranzuli (Puna de Jujuy, Argentina), from 1900 to the present. We will observe Argentinian State actions and in particular, how local actors negotiate from the urban form of the village, its own interests, from which it is possible to redefine and manipulate state hegemonic logic itself. In this framework, we propose to conceive villages as places, in which particularities it is possible to recognize singular ways of acting broader relationships, defined in a dynamic way.
\end{abstract}

Keywords: Andean Area, Urban planning, National State, Pastoralism

CONICET, Laboratorio de Arquitecturas Andinas y Construcción con Tierra, Instituto Rodolfo Kusch, Universidad Nacional de Jujuy. 


\title{
RESUMO
}

\begin{abstract}
As aldeias dos pastores nos Andes, e particularmente na Argentina, foram historicamente concebidos na tensão entre a dinâmica da mobilidade populacional e os interesses do Estado, focados na sedentarização da mesma, constituindo as aldeas em centros para o "processo civilizacional", baseado no binômio rural-urbano. Neste artigo, analisaremos, por meio de fontes gráficas e escritas, a evolução da forma urbana de Coranzulí (Puna de Jujuy, Argentina) de 1900 até os dias atuais, observando as ações do Estado argentino e, em particular, como atores locais negociei na e da forma urbana da aldeia seus próprios interesses, dos quais é possível redefinir e manobrar a lógica hegemônica do próprio Estado. É dentro desse processo que propomos conceber aldeias como lugares, em cujas particularidades é possivel reconhecer maneiras singulares de atuar relacionamentos mais amplos, definidos de forma dinâmica.
\end{abstract}

Palavras-chave: Área Andina, Planejamento Urbano, Estado Nacional, Pastoralismo.

La relación entre los estados nacionales y los grupos nómadas o semi-nómadas en distintas partes del mundo ha sido históricamente conflictiva (Salzman, 1980; Khazanov, 1994; Turner, 2009). La movilidad de los pastores constituyó un problema concreto para el control social y económico de la población, en el marco de la conformación política de los estados modernos. En el contexto argentino, las movilidades de los pastores cordilleranos han sido objeto de diferentes políticas públicas destinadas a sedentarizar a la población y establecer a la cordillera de los Andes como un límite en la frontera interestatal argentino-chilena, lo que estuvo asociado a procurar el desmantelamiento de un espacio que desde tiempos prehispánicos había sido un ámbito pleno de intercambios, desplazamientos y habitantes (Molina Otarola, 2008). En particular, en lo que refiere al área puneña, localizada en el actual norte argentino, los pastores se han caracterizado por poseer un patrón de asentamiento mayormente disperso y múltiple, ligado al pastoreo de alta movilidad -principalmente de llamas, cabras y ovejas- como actividad productiva principal (Yacobaccio et al., 1998; Delfino, 2001; Göbel, 2002; Abeledo, 2008; Tomasi, 2011). Esto resultó conflictivo para las estructuras regulatorias del Estado Nacional para las que la sedentarización de la población formó parte de su proceso de reconformación identitaria. En palabras de Svampa (2006), se trató de espacializar la oposición entre barbarie y civilización a través del binomio rural-urbano.

En los contextos locales, la noción de pueblo, además de designar a un asentamiento más o menos conglomerado, tiene sus propias implicancias en el marco de las dinámicas pastoriles. Entonces, cuando el Estado habla de los "pueblos" y cuando lo hacen los pastores, aunque se refieran al mismo lugar, no necesariamente lo están definiendo y habitando de la misma manera. Precisamente en esta tensión se enfocan los intereses de este artículo, a partir del análisis de la materialidad de la forma urbana del pueblo de Coranzulí, en la Puna de la provincia de Jujuy, Argentina. Los pueblos puneños han sido, históricamente, espacios significativos tanto para el desarrollo de las estrategias de sedentarización del Estado Nacional como para los sistemas de asentamiento pastoriles. En otras palabras, los pueblos pueden ser considerados como espacios simultáneamente estatales y pastoriles, y por lo tanto están sujetos a las dinámicas de la relación entre los respectivos agentes -el Estado y los pastores-, atravesada por sus diversos intereses. Nos interesa analizar la conformación de estos pueblos en su dimensión espacial desde la noción de lugar (Massey, 2004), comprendiéndolos como nodos en los que convergen de un modo específico, procesos, relaciones y dinámicas que se construyen a diferentes escalas y en los que intervienen diferentes actores, con lógicas y sentidos muchas veces contrapuestos. 
El objetivo de este artículo es visibilizar las múltiples interacciones entre las agencias estatales y los actores locales, partiendo de la reconstrucción de los procesos de conformación de la forma urbana del pueblo de Coranzulí. Plantearemos la hipótesis que no es posible considerar la conformación del espacio en el pueblo como parte de procesos impulsados unilateralmente por el Estado y por lo tanto ser comprendida únicamente bajo los parámetros oficiales. Por el contrario, existen características específicas de la forma urbana del pueblo que forman parte de procesos y sentidos construidos localmente y que lo significan como tal en clave pastoril. A su vez, es también en el modo en que las propias lógicas estatales se reprodujeron en el pueblo, desde los intereses y acciones de los diferentes actores, que se visibilizan las agencias locales. Este artículo se desprende de una investigación más amplia² con un enfoque eminentemente etnográfico, que analiza a los pueblos y sus materialidades en tanto espacios de disputa y negociación, en el marco de relaciones políticas, económicas y sociales que se han establecido entre las lógicas hegemónicas encarnadas por las agencias estatales y las propias de los pastores. Recurriremos al análisis de distintos registros documentales, gráficos y escritos, para comprender las dinámicas experimentadas por la forma urbana de Coranzulí a lo largo de los siglos XX y XXI. Estos registros son: fotografías, planos, información estadística proveniente de los diferentes relevamientos poblacionales nacionales y locales, y registros documentales escritos, provenientes de las Memorias del Ministerio del Interior (Archivo General de la Nación -en adelante AGN-) y del Libro Histórico de la Escuela de Coranzulí.

En términos generales, nos referimos a la forma urbana como el modo en que están ordenados los espacios públicos y los espacios parcelados, cuya diferenciación, desde la perspectiva de la planificación urbana, caracterizó a los espacios urbanos diferenciándolos de los rurales (Noguera, 1981). Más allá de las complejidades que la oposición urbano-rural supone, las que han sido problematizadas tanto desde la geografía (Capel, 1975; Hiernaux y Lindón, 2006; entre muchos otros) como desde la sociología (Baigorri, 1995), esta aproximación a la condición física de la forma urbana resulta útil aquí para analizar el modo en que se ordena su materialidad ${ }^{3}$, desde la cual podremos aproximarnos a cómo a lo largo del siglo XX, se fueron estableciendo diálogos entre las agencias estatales y los actores locales. Su estudio nos permitirá observar el modo en que se ordenan los objetos en el pueblo de modo simultáneo y articulado con las ideas, intereses y modos de uso que allí se están definiendo. Evidentemente, problematizar el espacio del pueblo implicaría avanzar sobre una multiplicidad de objetos y acciones (sensu Santos, 2006) que van desde la vida doméstica hasta las celebraciones comunitarias y eventos públicos. Sin perjuicio de ello, en este trabajo nos enfocaremos en la forma urbana, como ámbito en que se definen y se materializan de un modo significativo, las ideas y las prácticas de los grupos sociales en tanto colectivos, y de las agencias estatales en el marco de las políticas públicas.

La problemática planteada para este trabajo encuentra un antecedente en el interés que se les ha dado a los pueblos en los Andes desde el campo académico. Si bien los estudios andinos -principalmente etnográficos- tendieron a privilegiar la descripción y análisis de la vida de los

Este artículo surge de la investigación realizada por la autora entre los años 2012 y 2017, en el marco de una Beca Doctoral del CONICET (Barada, 2017).

3 La noción de materialidad comprendida en un sentido relacional (Miller, 2005; Latour, 2008) resulta pertinente para referirnos a la forma urbana y a las arquitecturas de Coranzuli. Como también ha sugerido Nielsen, "la materialidad puede caracterizarse como el proceso mediante el cual los materiales (por ejemplo, artefactos, edificios, geoformas) y los actores sociales, objetos y sujetos, se constituyen mutuamente a través de la práctica" (2010:331) 
pastores en el área rural y los pueblos ocuparon un rol secundario, muchas de las ideas y sentidos que, en efecto, se han construido sobre estos serán problematizadas a la luz de los objetivos de este trabajo.

A partir de una lectura del rol de los pueblos en los estudios andinos, se observa que hubo dos tendencias principales: por un lado, el pueblo ha sido considerado como un espacio que cumple un rol específico en el sistema de movilidades y asentamientos de las unidades domésticas (Albó, 1972; Martínez, 1985; Abercrombie, 2006 [1978]; Tomasi, 2011; entre otros). Son las ceremonias y asambleas locales las que atraen a aquellos que viven en los cerros a asistir al pueblo en momentos específicos y lo significan como -diremos en principio-, espacialidad en clave pastoril. Por otro lado, los pueblos han sido considerados como espacios disruptivos para las dinámicas sociales pastoriles (Bolsi y Gutiérrez, 1974; Göbel, 2002; Allen, 2008). En este último tipo de clasificaciones, ha sido central el rol que los estados tuvieron como agentes principales en su desarrollo material.

Frecuentemente, estas dos miradas sobre los pueblos han sido planteadas de un modo contrapuesto. Sin embargo, los pueblos ipueden ser comprendidos como lugares de lo colectivo en un sentido que tiende a articular grupos y dinámicas sociales que se constituyen en el ámbito rural, o bien, pueden ser considerados lugares transformadores de esas mismas relaciones a la luz de los vínculos que han ido estableciendo estas poblaciones con los estados? En todo caso, resulta interesante destacar que, más allá de la alternancia o coexistencia de estas condiciones en la bibliografía, podemos encontrar una constante: la referencia a los pueblos como sitios deshabitados. Se trata de espacios con una alta significación, aun cuando no se trate de espacios de residencia permanente. Entonces, ¿cómo los pueblos se constituyen como lugares?

Proponemos que es a partir de la noción de lugar definida por Doreen Massey (1994; 2004), que es posible visibilizar nuevas aristas en las tensiones y conflictos de intereses por el espacio que redefinen esta aparente contraposición. Como ha propuesto esta autora, para pensar al lugar en el contexto actual es necesario debatir sobre su re-conceptualización a la luz del proceso de revisión teórica que atravesó la propia noción de espacio, especialmente desde la década de 1970. En este sentido, si el espacio es considerado un constructo social histórico, producto de la intersección de diferentes redes, relaciones y procesos que se dan de un modo simultáneo a diferentes escalas, el lugar no puede ser algo simple, cerrado y coherente. Esta perspectiva pretende superar la visión "reaccionaria de quienes observan en él una especie de refugio a la inseguridad que provoca el proceso de comprensión espacio-temporal" (Barros, 2000:88), por aquella que nos permite comprenderlo, por el contrario, como un ámbito desde el cual es posible para las personas construir identidades dinámicas desde las cuales negociar las acciones de los agentes hegemónicos.

En lo que sigue, nos aproximaremos al caso de estudio destacando sus singularidades y aquellos aspectos que resultan particularmente relevantes de su presente, para luego focalizar sobre su análisis histórico. Luego, abordaremos específicamente el estudio de la forma urbana de Coranzulí a través del tiempo, distinguiendo tres períodos en su desarrollo. El estudio de estos procesos en el tiempo nos permitirá construir la idea del pueblo como un lugar en el que agentes estatales y locales disputan sus ideas y acciones, pero por sobre todo, nos permitirá reconocer que estas no son unívocas ni lineales, cuestiones a ser discutidas hacia el final del trabajo. 


\section{Aproximaciones al caso de estudio}

Coranzulí es un pueblo de la Puna de la provincia de Jujuy, ubicado en el departamento de Susques, a $70 \mathrm{~km}$ de la cabecera departamental homónima. Está atravesado por dos vías de comunicación de cierta envergadura. La Ruta Nacional 40 lo vincula con Susques hacia el sur y con Mina Pirquitas hacia el norte. La Ruta Provincial 74 lo conecta con la ciudad de Abra Pampa y desde allí, a través de la Ruta Nacional 9, con San Salvador de Jujuy -capital provincial- localizada a $260 \mathrm{~km}$ de Coranzulí (Figura No1). Durante el período republicano, ha tenido la singularidad de pertenecer a diferentes Estados Nacionales. En el marco de los procesos independentistas latinoamericanos llevados a cabo durante el siglo XIX, primero formó parte de Bolivia hasta 1879 y luego, durante la Guerra del Pacífico, pasó a formar parte de Chile (Delgado 2003; Benedetti, 2005). En 1899, con la firma del laudo Buchanan, se estableció el límite definitivo entre Chile y Argentina (Benedetti, 2005) y el sector oriental de las tierras altas atacameñas donde se localiza Coranzulí -que para entonces se denominaba Puna de Atacama-, pasó a formar parte del territorio argentino. Desde 1900 hasta 1943, estuvo incluido en el Territorio Nacional de Los Andes -en adelante TNLA- y desde su disolución fue incorporado, junto con el resto del departamento de Susques, a la provincia de Jujuy (Benedetti, 2005).

Desde 1969, Coranzulí es cabecera de la Comisión Municipal del mismo nombre, con un territorio que abarca unos $2.926 \mathrm{~km}^{2}$, y de la que dependen otras cuatro localidades rurales. En términos poblacionales, fueron registrados para esta localidad en el último Censo Nacional de

Figura No1

Mapa de la provincia de Jujuy en el que se destacaron la localización de Coranzulí y las localidades y rutas mencionadas

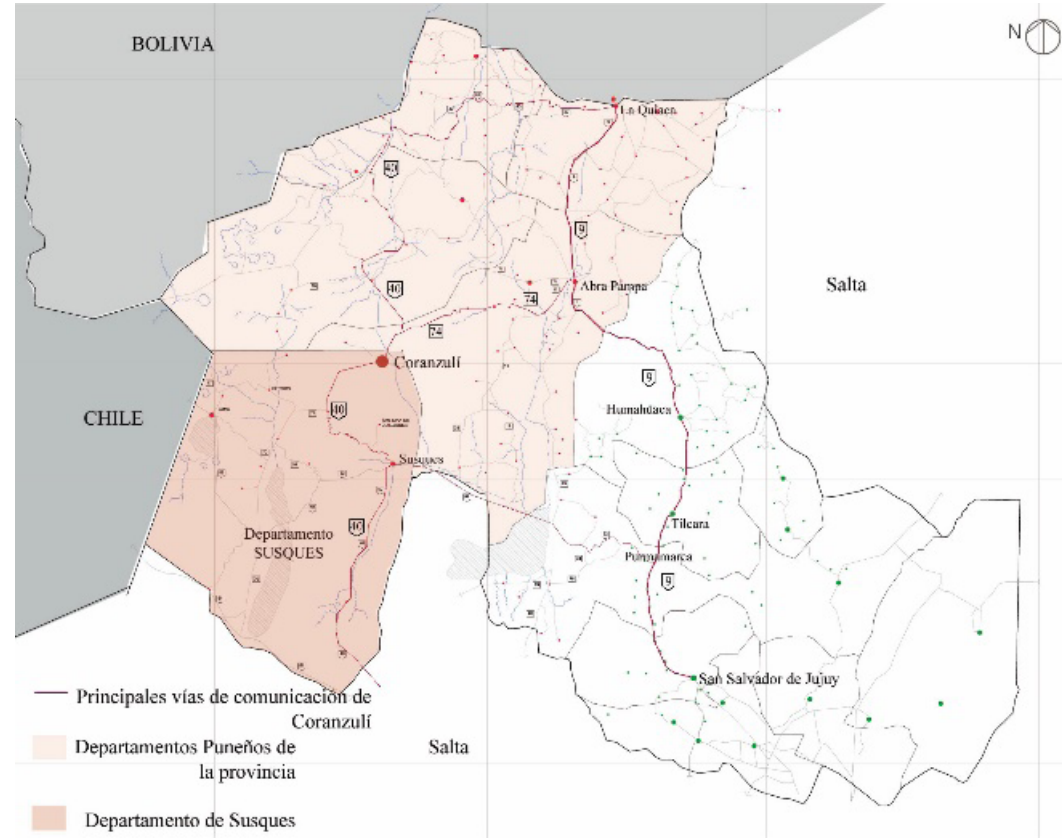

Fuente: elaboración propia sobre base de mapa de la provincia de Jujuy, Instituto Geográfico Nacional. 
Población y Vivienda (INDEC, 2010), un total de 333 habitantes. El pueblo de Coranzulí es también sede de diferentes instituciones del Estado Provincial: una escuela primaria y secundaria, una unidad sanitaria, un registro civil y un destacamento policial. Es también sede de otras instituciones comunitarias, como el Centro Vecinal y la Comunidad Aborigen. Allí se encuentra, también, una capilla para el culto católico -desde 1899- y otra para el culto evangélico -desde 1950-. Finalmente, desde una perspectiva rural, Coranzuli es el centro de un área de pastoreos que se encuentra actualmente dividida en tres secciones en las que se distribuyen los territorios de pasturas de cada una de las familias locales. Hablar de Coranzulí implica definirlo como un locus en el que intervienen todas estas instituciones, dependencias administrativas, construcciones geográficas, agentes políticos y locales, de un modo simultáneo.

\section{Dinámicas históricas en Coranzulí, la forma urbana en tensión}

Para este análisis, definimos tres períodos históricos, cada uno de ellos atravesado por sucesos significativos en el marco de los procesos políticos y económicos en los que se inscribe la relación entre Coranzulí y las estructuras políticas del Estado Nacional Argentino en el tiempo. El primero se define con su incorporación a la Argentina y da cuenta de las dinámicas previas e inmediatamente posteriores, en las primeras décadas tras su anexión en 1900. El segundo está comprendido por la pertenencia de Coranzulí al TNLA hasta 1943 y el período inmediatamente posterior a su anexión a la provincia de Jujuy (1943-1969). Este estará atravesado por la ausencia de órganos de gobierno local que operasen en el pueblo, lo que conlleva a una acción más o menos directa del gobierno nacional -sobre los Territorios Nacionales- y más tarde del gobierno provincial. El tercer y último período se inicia con la conformación de Coranzulí como Comisión Municipal de la provincia de Jujuy en 1969 y alcanza a la actualidad.

\section{Coranzulí y su anexión a la Argentina}

Hemos mencionado que Coranzulí tuvo sucesivas pertenencias nacionales durante el período republicano. Fue entonces luego de la finalización de la Guerra del Pacífico y del establecimiento de un tratado internacional con Chile en 1899, que las tierras del oriente atacameño donde se encontraba Coranzulí, pasaron a formar parte de la jurisdicción del territorio nacional argentino. En 1900 fue creado el TNLA y organizado en tres departamentos, de sur a norte: Antofagasta de la Sierra, Pastos Grandes y Susques. Posteriormente, se anexó el Departamento de San Antonio de los Cobres -cedido por la provincia de Salta- que funcionó como capital del territorio hasta su disolución final en 1943.

Coranzulí quedó integrado dentro del departamento de Susques. Para dicho momento, se trataba de un núcleo urbano de reducidas dimensiones, caracterizado por la presencia de la capilla y unas pocas construcciones a su alrededor. Podemos ilustrar esto a partir de uno de los relatos locales que se elaboraron sobre la fundación del pueblo, en el que se evidencia su conformación de un modo "independiente" de los procesos políticos experimentados por el área: "En el año 1899 se fundó este hermoso pueblo, por aquel entonces era un lugar de una casa abandonada y nada más (...) vecinos de los alrededores (...), se pusieron de acuerdo para dar vida a este lugar al que denominarían Coranzulí. En primer término, con el apoyo de los vecinos del lugar, se creó 
la capilla. (...."4. En una primera lectura de este relato, se observa cómo el "lugar" del pueblo se define desde una clave local, considerando -a través de la creación de la capilla- a Coranzulí como un sitio de significación colectiva que articularía a las familias de pastores residentes mayormente en el campo.

El Gral. Daniel Cerri, primer gobernador del TNLA, tomó la primera fotografía que tenemos sobre Coranzulí en 1900, evidencia del modo en que este poblado se había configurado antes de su incorporación a la Argentina. En esta puede observarse el conjunto conformado por la capilla y el cementerio. La capilla está constituida por un recinto rectangular circundado por su atrio, dentro del cual se localiza una torre exenta y cuatro capillas posas ${ }^{5}$ en las esquinas (Figura $\mathrm{N}^{\circ} 2$ ). Los accesos al atrio y la iglesia están alineados y orientados al este. El cementerio, asociado al atrio, se encuentra al norte del mismo. Entorno a este conjunto se ordenan otras cuatro construcciones que podemos suponer de uso doméstico, cada una de ellas constituida por un único recinto rectangular y con su abertura orientada al este. La conformación de los terrenos es difusa y no parece haber límites entre el espacio que ocupa una y otra construcción.

En términos del propio Cerri: "El aspecto general de esta aldeíta, compuesta de ocho o diez ranchos alineados, con su buena capilla y cementerio, es bastante atrayente, pues forma un contraste lo colorado vivo de sus paredes con el verde de las vegas situadas al pie de aquel cerro (...) Los nativos, bolivianos puros, no habitan el caserío, estacionan en las vegas con sus rebaños de llamas, ovejas y cabras" (Cerri 1993 [1903]:55). Esta descripción es una primera lectura de ese "lugar", desde un agente estatal. En esta, se destaca la alineación de los "ranchos" que observamos en la fotografía y la presencia de la capilla y el cementerio, objetos que han caracterizado la génesis de los poblados indígenas durante el período colonial. Sin embargo, los procesos históricos indican que Coranzulí no fue constituido como una verdadera reducción de indios durante la colonia, y observamos dos cuestiones significativas en este mismo sentido en el relato de Cerri. La primera tiene que ver con el tipo de ordenamiento que se observa, que no responde a una lógica urbana asociada al urbanismo indiano, sino que se trata de una alineación de las casas con sus aberturas hacia el este. Esto reproduce la lógica registrada por Tomasi (2011) para los domicilios en el campo, cuyas puertas y ventanas preferentemente se encuentran orientadas hacia el sol naciente, al igual que la de la iglesia y su atrio. La segunda refiere a la afirmación que las personas no habitaban allí, sino que mantenían sus residencias en el campo. Es decir, el pueblo en tanto lugar se constituía como un sitio de significación para la población local asociado a la presencia de la iglesia, pero no como un lugar de residencia. Para complementar estas ideas, podemos traer otra descripción realizada por Holmberg, comprendida en el marco de los relatos que distintos viajeros construyeron a partir de sus recorridos por el área desde finales del siglo XIX y a comienzos del siglo XX (Castro, 2007; Tomasi, 2015). "Estas reuniones de familias no alcanzan a tomar aspecto de pueblos, son simples caseríos, cuya distribución se ha hecho obedeciendo a las formas del terreno: amontonamiento desordenado de ranchos. Antofagasta, Susquis, Coranzuli y Santa Rosa de Pastos Grandes, son las principales poblaciones. Han sido edificadas junto a las capillas que las tres poseen" (Holmberg, 1900:75).

Fragmento del relato fundacional del pueblo, reproducido en el marco de sus Fiestas Patronales.

Conocidas también como ermitas, estas capillas son capillas semi-abiertas que, en general, se localizan en las esquinas de los atrios en las iglesias americanas coloniales. 
Figura $\mathrm{N}^{\circ} 2$

Recorte de la fotografía de Cerri con indicación de las construcciones descriptas.

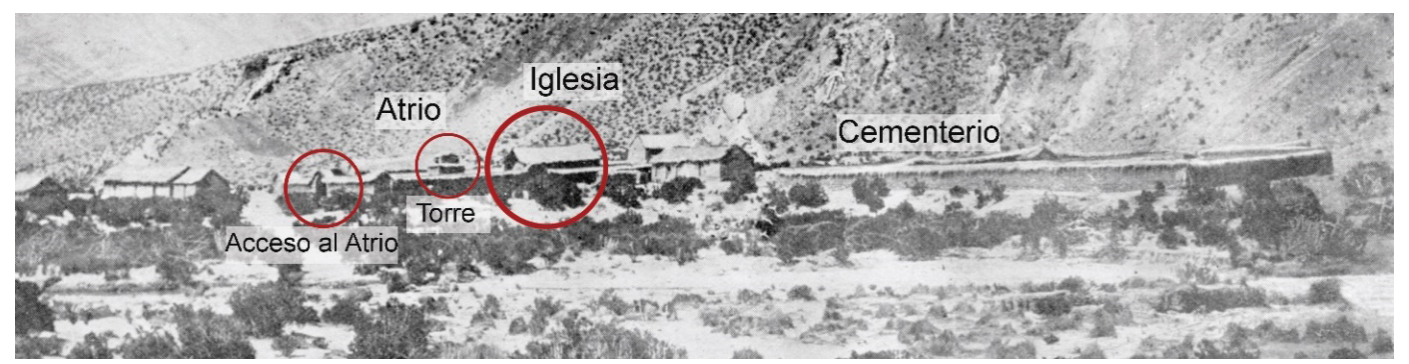

Fuente: elaboración propia en base a Cerri, 1993 [1903].

Este "desorden" y su relación con esta ausencia de población en el pueblo, nos lleva a reforzar la idea de una necesaria articulación de este lugar con las dinámicas que ocurrían en el campo. En relación con esto podemos traer una tercera referencia. Es la que elabora Boman (1991 [1908]) para el poblado de Susques en 1908. Allí, él señala la presencia de cuatro calvarios que designó como apachetas, localizados en los cuatro puntos cardinales del poblado. Si bien no contamos con un relato que hable de su presencia en Coranzulí para comienzos del siglo, la cercanía y las relaciones que existían entre la población de ambos lugares, nos permite pensar que estos elementos se encontraban por entonces en ambos sitios ${ }^{6}$. Lo relevante de esto en relación con la definición de Coranzulí como un lugar estrechamente vinculado a las dinámicas pastoriles, es que se trata de elementos demarcatorios de los límites del poblado que articulan, en términos materiales y simbólicos, las espacialidades del campo y del pueblo, participando de manera activa en la producción de sus límites y demarcación de recorridos, encontrando similitudes con lo que sucede con las apachetas y mojones (Vitri, 2002; Galdames et al., 2016). Por su localización, los calvarios deben ser atravesados para salir del pueblo y es en esa instancia en la cual los viajeros y los peregrinos que se dirigen a participar de alguna celebración religiosa en otro poblado, los challan?. Esto permite reforzar la idea del pueblo como un sitio de referencia, de significación, para una población que residía en el campo y que en todo caso acudía al pueblo en momentos puntuales.

Además de existencia de Coranzulí en tanto lugar para la población local, también se definía como un lugar en relación con otras poblaciones del área, con dinámicas que por entonces se mantenían más o menos al margen de las estructuras estatales (Sanhueza, 2001). De hecho, encontramos una serie de documentos, en su mayoría correspondencias ${ }^{8}$ entre funcionarios que recorrían por entonces la zona y las autoridades nacionales, en los que exponen, incluso con cierta preocupación, la idea de la existencia de un cierto margen de maniobra por parte de los pobladores del área ante las estructuras de Estado, e incluso relatan acciones explícitas de rebeldía ante la autoridad nacional. Entre estas, es posible reconocer una serie de relatos de episodios, sucedidos entre los años 1900 y 1903, vinculados al "desacato" que los pobladores de Coranzulí ejercieron sobre las autoridades argentinas. En primer lugar, se registraron eventos en los que la

\footnotetext{
Suma a esta hipótesis el hecho que los calvarios están presentes en el actual del pueblo de Coranzulí, como observaremos más adelante. En la actualidad en Coranzulí, los calvarios suelen ser utilizados, también, en las Fiestas Patronales.

Los documentos consultados para esta problemática conforman el Libro Copiador del Territorio Nacional de los Andes, Archivo General de la Nación, Series Históricas III.
} 
población del área reivindicaba su pertenencia a Bolivia, a través de acciones que involucraron la quema de una bandera argentina (Boman, 1991 [1908]). En segundo lugar, se reconocen comunicaciones a través de las cuales los coranzuleños negociaron su aceptación de pertenencia al Estado Nacional Argentino a cambio de "no ser molestados en sus casas"9. Nuevamente, la cuestión del sostenimiento de una residencia en el campo, se posiciona como central. En relación con esto último, podemos avanzar entonces sobre las dinámicas poblacionales de Coranzulí en los años posteriores a la visita de Cerri, a partir de los primeros relevamientos realizados por funcionarios del TNLA (Cuadro No1).

\section{Cuadro No1}

Datos poblacionales de relevamientos realizados entre 1900 y 1920 en el Territorio Nacional de Los Andes.

\begin{tabular}{|c|c|c|c|c|l|}
\hline Año & $\begin{array}{c}\text { Total } \\
\text { Territorio }\end{array}$ & $\begin{array}{c}\text { Departamento } \\
\text { Susques }\end{array}$ & Susques & Coranzulí & \multicolumn{1}{|c|}{ Fuente } \\
\hline 1900 & 507 & - & 94 & 58 & $\begin{array}{l}{ }^{*} \text { Censo de Territorio Nacional de Los } \\
\text { Andes. 1900. Ml. }\end{array}$ \\
\hline 1901 & 1.149 & 671 & 521 & 150 & $\begin{array}{l}{ }^{*} \text { Carrasco (1901). Nota: Este es el único } \\
\text { caso en el que Coranzuli aparece es- } \\
\text { cindido del Departamento de Susques. } \\
\text { Las poblaciones consignadas para } \\
\text { cada caso no corresponden solamente } \\
\text { a los poblados de Susques y Coranzulí } \\
\text { sino también a sus respectivas áreas } \\
\text { rurales. Tomado de: Benedetti (2005). }\end{array}$ \\
\hline 1912 & 2.348 & 855 & 318 & 211 & $\begin{array}{l}{ }^{*} \text { Censo de Población de Territorios Na- } \\
\text { cionales de 1912. MI. }\end{array}$ \\
\hline 1920 & 2.539 & 1.025 & 259 & 224 & $\begin{array}{l}{ }^{*} \text { Censo de Territorios Nacionales 1920. } \\
\text { Ml. }\end{array}$ \\
\hline
\end{tabular}

Fuente: elaboración propia a partir de las fuentes consignadas.

Como podemos observar en el Cuadro N01, la población registrada tanto para el TNLA como para el departamento de Susques se ha ido incrementando progresivamente desde el primer relevamiento realizado el mismo año de su creación y hasta 1920. Lo propio sucedió con los pueblos de Susques y Coranzulí, respectivamente. Como se observa, aun cuando la posición de Coranzulí dentro de la estructura político-administrativa del TNLA fuese más desfavorable que la de Susques, su población no posee una diferencia significativa, particularmente a partir de los relevamientos de 1912 y 1920. Esto permite pensar en la relevancia que mantenía Coranzulí como sitio de referencia para una población en principio residente en el campo, aun cuando esta estuviese asociada mayormente a sus propias dinámicas y relaciones y no a su incorporación efectiva en las lógicas de una organización político-territorial. En este sentido, podemos pensar que las primeras acciones impulsadas por la Gobernación por la reorganización del territorio en el marco

\footnotetext{
9 AGN, Libro del Copiador del Territorio de Los Andes 1902-1906, p.278 (tomado de Delgado, 2007). La voluntad de los coranzuleños por reivindicar su pertenencia a Bolivia y por lo tanto desconocer su pertenencia a la Argentina en años posteriores a la anexión de estas tierras también fue registrada en una comunicación de 1902 iniciada por el capellán de Susques al segundo Gobernador del Territorio (Archivo General de la Nación, Series Históricas III, signatura 65).
} 
de las estructuras del Estado Nacional, permitió el registro progresivo de la población local, mas no el desarrollo de una verdadera estructura urbana que redefina las dinámicas de residencia de los pastores. En otras palabras, el posicionamiento de Susques como cabecera administrativa no habría, por entonces, implicado una reorganización de las densidades poblacionales y sus dinámicas en el plano local.

\section{Coranzulí en el Territorio Nacional de Los Andes y su incorporación a Jujuy}

El TNLA fue disuelto en 1943. Una imagen fotográfica publicada un año antes, en 1942 (Figura No3) permite observar el desarrollo que la forma urbana de Coranzulí tuvo en este período ${ }^{10}$. Allí se observa un notable crecimiento en la cantidad de construcciones en el pueblo y un devenir de su forma urbana y arquitectónica que se complementa en otras dos fotografías tomadas en el mismo año, una de un sector del pueblo y otra de la iglesia (Figura $N^{\circ} 4$ ).

Figura $\mathrm{N}^{\circ} 3$

Coranzulí en la década de 1940

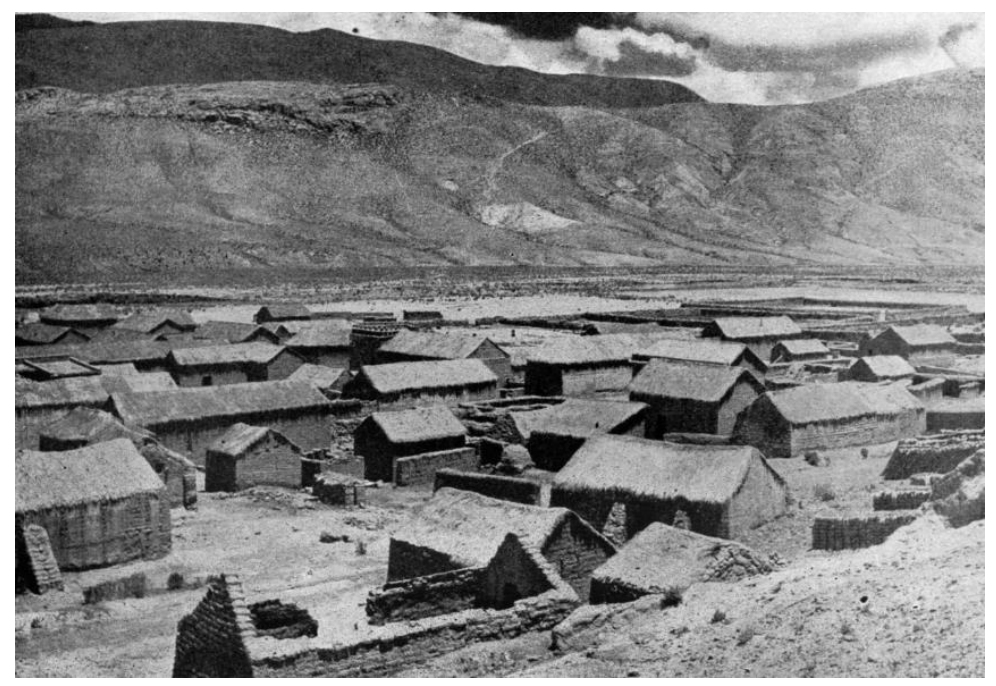

Fuente: fotografía de Hans Mann, Academia Nacional de Bellas Artes, 1942.

Podemos notar una ruptura en la linealidad que las casas tenían en el momento anterior, por una multiplicidad de construcciones, muchas de ellas configurando una forma de L. Así, la mayoría de estas casas ha dejado de estar compuesta por un único recinto, por lo que comienza reconocerse un ordenamiento continuo configurando calles rectas y perpendiculares entre sí, a la vez que hacia el interior de las incipientes manzanas se observa la presencia de ciertos vacíos que se definirían como patios. Esto nos permite pensar en la relación entre los recintos cerrados y un espacio exterior de uso doméstico cuya delimitación manifiesta una incipiente conformación de terrenos. Esto puede asociarse a las lógicas de conformación de la forma urbana planteadas al

10 Otros registros fotográficos del mismo autor permiten inferir que las fotografías fueron tomadas durante su viaje en 1939. 
comienzo, atravesadas por la noción estatal de diferenciación del suelo como condición para la estructuración de espacios urbanos.

Las fotografías permiten observar una más división entre terrenos, que se expresa, en la existencia de tapias, incluso, en ciertos sectores donde las manzanas no poseen construcciones. Podemos indagar, entonces, acerca de las lógicas que estarían interviniendo en la progresiva división de los terrenos, que conlleva a una partición de las incipientes manzanas. La investigación etnográfica realizada e incluso los catastros actuales del casco histórico del pueblo, dan cuenta de una cierta "familiaridad" entre las titularidades de terrenos vecinos que evidentemente posee una trazabilidad histórica en su conformación. Podemos plantear que esta pudo haberse ido organizando a través de la réplica de las lógicas de fusión y fisión de los pastoreos que predominan en el campo (Tomasi, 2011), considerando, entonces, dos alternativas para la progresiva conformación de terrenos en el pueblo. (1) El crecimiento de la casa se da en concordancia con la sucesión generacional de la familia, dando lugar a casas en las que conviven distintas generaciones de una familia" o bien (2) las construcciones se subdividen y conforman terrenos linderos cuyos propietarios poseen un mismo apellido, pero constituyen casas más o menos independientes. Es decir que hay una de separación de lo privado y lo público, con la definición de "la calle", que replica una lógica urbana "estatal", aun cuando esté operando un modo de hacer proveniente del modo de vida pastoril asociado a la reproducción de las unidades domésticas. Sin embargo, la información propiciada por fuentes documentales escritas, permite incorporar una tercera alternativa posible a la progresiva generación de terrenos en el pueblo que interviene sobre esta lógica familiar.

Se trata de un documento de $1928^{12}$, que corresponde a un pedimento de lotes realizado por dos pobladores de Coranzulí a las autoridades del TNLA ${ }^{13}$. Este es el único registro que poseemos sobre este tipo de dinámicas para Coranzulí durante la primera mitad del siglo XX, por lo que no podemos determinar si se trató de una práctica extendida. Sin embargo, en el marco de la tensión entre el proyecto estatal -definido por una búsqueda por una regularidad de las manzanas y la separación de un interior privado del exterior público-, y las dinámicas locales -definidas a partir de la progresión constructiva de las casas y la conformación de terrenos como productos del crecimiento de las familias en el tiempo-, nos resulta significativa la existencia de esta tercera alternativa, en tanto es la primera referencia sobre la definición de lotes en la que el Estado comienza a ocupar un papel preponderante.

Por otra parte, en la complementariedad entre los documentos escritos, gráficos, y el registro etnográfico, debemos destacar la presencia de las primeras instituciones cívicas. Estas se localizaban rodeando a la iglesia: la escuela y la policía. Por su parte, la imagen de la iglesia que ya había cambiado su apariencia desde la imagen de Cerri ${ }^{14}$, permite observar la presencia de un

La construcción de la casa en el tiempo y su relación con la sucesión general de la familia es un problema en sí mismo que ha sido abordado en otros trabajos para el área (Göbel, 2002; Tomasi, 2011; Barada, 2017; entre otros).

12 AGN, SH III, signatura 85. Carta del Jefe de Policía de Susques al Gobernador del Territorio de Los Andes enviada el 19 de diciembre de 1928. Se trata de un pedido de "dos vecinos de Coranzulí" que solicitan lotes para la construcción de sus casas. El Documento fue emitido por el Sub-Comisario de Coranzulí y dirigido al Gobernador del Territorio Nacional de Los Andes.

13 Es necesario aclarar que las tierras de la Puna de Atacama fueron declaradas fiscales desde la creación del TNLA y buena parte de ellas continúa sosteniendo dicha condición al día de hoy.

14 Si bien excede los objetivos de este artículo ahondar en las características específicas de las arquitecturas del pueblo, podemos decir que es a partir de este momento que la iglesia comienza a experimentar notables modificaciones en su arquitectura, hasta adquirir su forma actual (Barada, 2018a) 
mojón con una cruz. Esta estructura -que no se visibiliza en la imagen previa de Cerri- implica la trascendencia del ámbito de la iglesia más allá del atrio, articulándose directamente con el espacio urbano.

Figura $\mathrm{N}^{\circ} 4$

Un sector de Coranzulí y su iglesia.
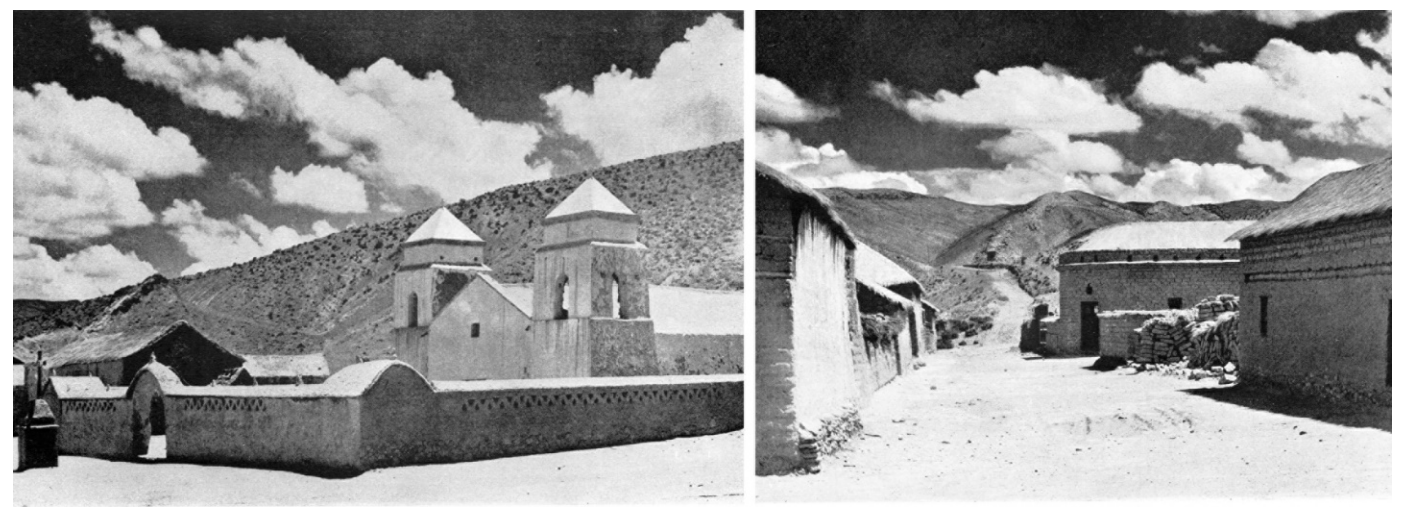

Fuente: fotografía de Hans Mann, Academia Nacional de Bellas Artes, 1942.

En relación con el correlato poblacional de este desarrollo, no se cuenta con información estadística específica para este período luego del conteo de 1920. Sin embargo, sí encontramos un registro interno, correspondiente a un relevamiento realizado por los propios maestros de la escuela de Coranzulí, en el año 1940. Este da cuenta de un total de 285 personas. Podemos notar que no hubo un cambio significativo en comparación con la cantidad de población que había sido registrada por el Censo de Población de Territorios Nacionales en 1920. A propósito de ello, podemos observar lo señalado por los maestros en dicho libro sobre las características del relevamiento realizado, dando cuenta que este no incluyó únicamente a la población que efectivamente residía en el pueblo, sino que contempló a las familias que vivían en el campo. "Se procede a enviar sin pérdida de tiempo a recoger los datos pedidos en Cédulas Individuales a todas las personas que viven en lugares muy distantes y que suman decenas de kilómetros. Mientras tanto, en todos los días subsiguientes se continuará dicho trabajo en los que viven más o menos cerca..." (Mes de Noviembre de 1940). De este modo, si el conteo incluyó a las familias en el campo y su resultado no dista del obtenido dos décadas antes, podemos pensar que, aun al momento de disolución del TNLA, la población de Coranzulí no vivía en el pueblo, incluso cuando gran parte de los niños ya estuviesen escolarizados y las instituciones del Estado operasen allí.

En relación con esto último es que resulta significativo sintetizar algunos de los aspectos observados para este período. Si volvemos sobre la imagen de la Figura No3, debemos reconocer el notable crecimiento que experimentó el pueblo desde el registro anterior en 1900, aun cuando, por un lado y tal como vimos, no haya sido objeto de políticas urbanas específicas. Es decir, la forma urbana de Coranzulí, que comienza a mostrar un progresivo ordenamiento del tejido y en particular, una división entre lo público y lo privado, responde a un desarrollo que no ha sido reglamentado ni ordenado de manera directa, sino que por el contrario fue mayormente propiciado desde los actores locales. Por el otro, y tal como se observa en el relato consignado por los maestros en el libro acompañando el relevamiento de 1940, la población aún no vivía allí. 
Entonces, ¿Cuáles son las ideas y sentidos que intervinieron en esta conformación de la forma urbana de Coranzulí?

De este modo es necesario ampliar la mirada para comprender, en la clave de Massey (2004) no sólo la especificidad del pueblo como lugar, sino sus relaciones. Debemos considerar, entonces, los vínculos -sociales, rituales e incluso familiares- que su población tenía con la población de otros centros poblados y que preexistían a la intervención estatal en el área y la consecuente conformación del TNLA y su organización administrativa (Delgado, 2007). Las fuentes documentales escritas analizadas por esta autora ${ }^{15}$ evidencian vínculos de Coranzulí con otros sitios que, como Cochinoca o Abra Pampa, ya pertenecían a la provincia de Jujuy -y por lo tanto al Estado Argentino-, desde la declaración de la autonomía de esta, en 1834. En efecto, es a través de estas relaciones que los coranzuleños negocian su propia incorporación al Territorio de los Andes, en tensión con los intereses que ellos mismos tenían sobre la entonces jurisdicción boliviana y en el territorio argentino sobre las provincias de Jujuy y Salta (Barada, 2017). Analizar estos procesos excede los objetivos de este artículo, pero resulta necesario considerarlos en función de comprender el desarrollo urbano que Coranzulí poseía en la década de 1940, comparable con el de centros poblados como Abra Pampa o Cochinoca (Figura N05), y en contraposición al que para entonces poseía el propio Susques, cabecera departamental en el Territorio Nacional (Tomasi, 2012). En este sentido, podemos afirmar que, por un lado, los coranzuleños conocían otras experiencias urbanas a través de sus propios vínculos intercomunitarios que excedían a la lógica del ordenamiento del TNLA. Por el otro, que el desarrollo de la forma urbana de Coranzuli siguió estos patrones aun cuando no haya habido políticas específicas sobre su espacio y, lo que es incluso más llamativo, cuando la población no residiese en el pueblo. Esto último es particularmente relevante para remarcar en el marco de un contexto en el cual, como vimos, es la propia población local la que negociaba su condición ante el Estado desde la capacidad de maniobra que brindaba la condición "periférica" que el propio Estado definió en sus procesos de conformación territorial.

Figura No5

Imágenes de Cochinoca en 1926 (izq.) y de una calle de Abra Pampa en 1945 (der.)
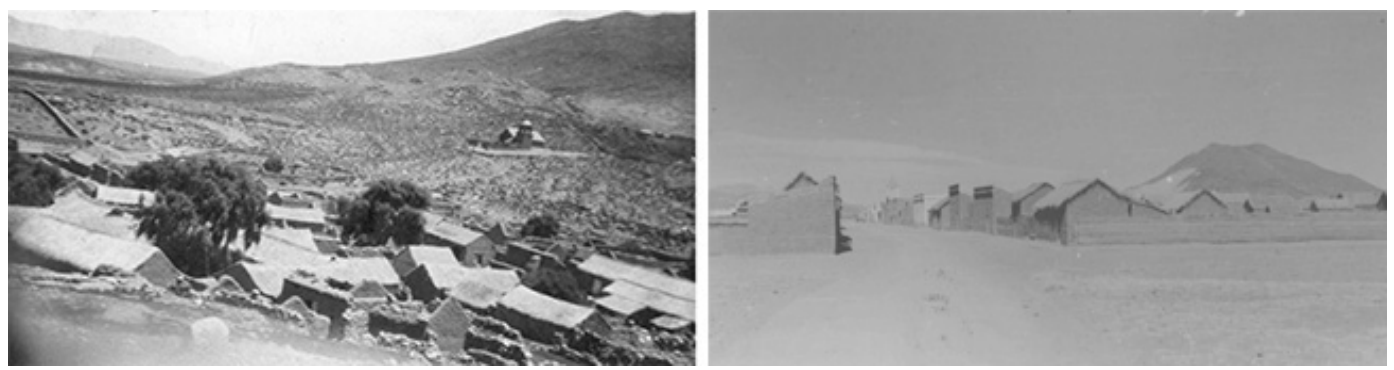

Fuente: Archivo General de la Nación. Departamento de Documentos Fotográficos. 


\section{Coranzulí desde su creación como Comisión Municipal de la provincia de Jujuy al hoy}

Ha sido entre las décadas de 1960 y 1970 que Coranzulí se incorporó de manera efectiva a las estructuras político-administrativas provinciales, luego de un extenso período de traspaso de lo que fuera el departamento norte del TNLA a la administración de Jujuy, en el cual se registran escasas acciones por parte de la provincia sobre el territorio (Barada, 2017). El suceso más significativo en este sentido se dio recién en 1969, con la creación de las Comisiones Municipales de Coranzulí y Susques. En términos urbanos, las fuentes gráficas halladas nos permiten observar una contundente delimitación de manzanas en toda la extensión del pueblo, con un incremento notable en la densidad de las construcciones respecto del momento anterior $y$, también, evidencia los inicios de un llamativo cambio técnico-constructivo en las arquitecturas. Las ochavas y frentes continuos que aparecieron de modo incipiente en los registros gráficos correspondientes al momento de la disolución del TNLA, se observan ahora, de un modo mucho más claro (Figura N6).

Figura $\mathrm{N}^{\circ} 6$

Coranzulí en 1970

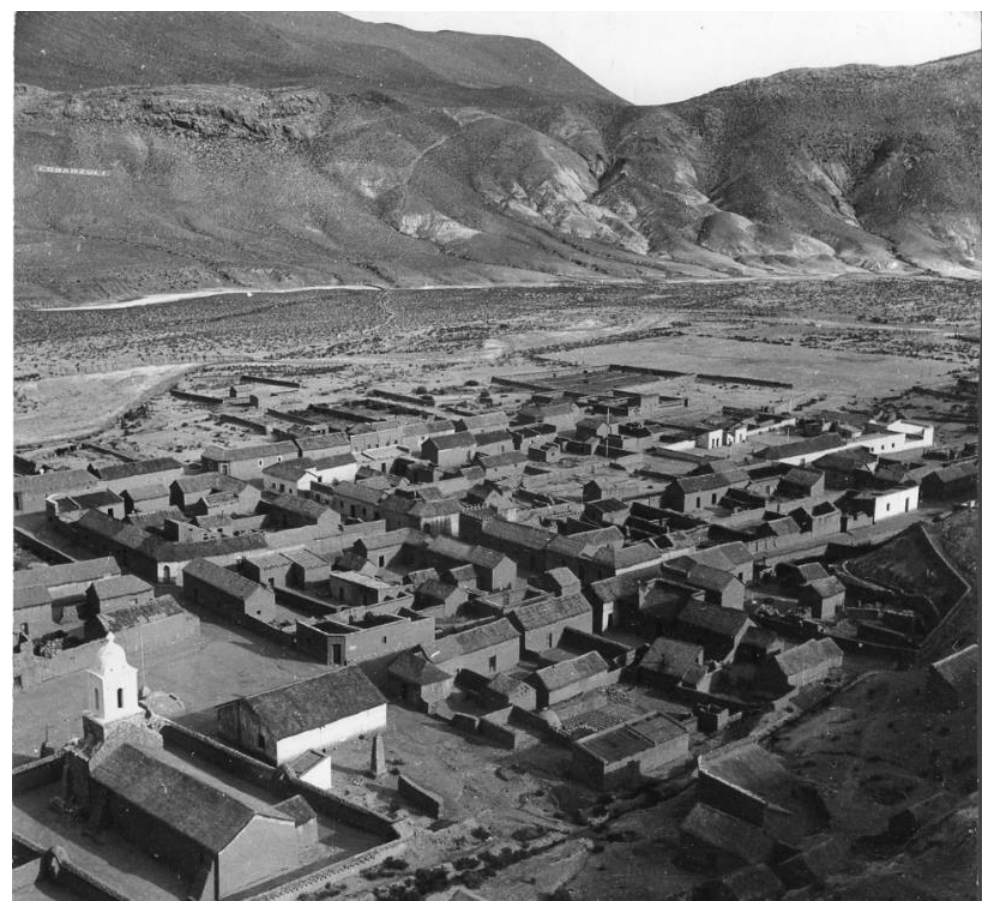

Fuente: Fotografía inédita de Federico Ortíz, CEDODAL.

Las manzanas aparecen consolidadas prácticamente en sus cuatro lados. Los límites entre el espacio exterior -la calle- y los interiores de las construcciones -los patios- se distinguen de un modo más definido que en la década de 1940. Esta diferenciación permite reconocer los trazados de las calles cuyos cruces se delimitan a partir de la presencia de esquinas, algunas de ellas en ochava. En particular, esta forma urbana se observa en las manzanas que se han densificado más tardíamente, localizadas hacia el sur, mientras que en lo que correspondería al "tejido fundacio- 
nal" en torno a la iglesia, mantuvo una conformación más irregular. En la diferencia entre estos dos esquemas de ordenamiento del tejido, podemos observar la presencia de diferentes lógicas de conformación de terrenos. La primera se corresponde con las alternativas de fusión y fisión observadas para el momento de la disolución del TNLA. La segunda es la que se introdujo a partir de la creación de la Comisión Municipal en 1969. A partir de entonces, este ha sido este organismo estatal de orden local el que comenzó a regular la ocupación de los terrenos y las lógicas de tenencia de la tierra definiendo la figura del lote: una porción de la manzana limitada previamente, dentro de la cual se inscribe la casa de una familia. El mecanismo para la obtención de lotes para la construcción por parte de las familias es regulado por la Comisión Municipal y se mantiene hasta el día de hoy.

En función de comprender la continuidad de estas dinámicas y sus estrategias actuales, debemos considerar que la década de 1970 se define como un momento de significativas transformaciones económicas y sociales para los poblados del departamento de Susques. La intensidad de los mercados laborales mineros y la expansión del comercio aparecen mucho más claramente en la vida cotidiana de los pueblos, intensificando el desarrollo de las "actividades urbanas" (Tomasi, 2011). Como han descripto Merlino y Rabey (1978) en su visita a Coranzuli: “La casi totalidad de los varones jóvenes trabajan en Mina Pirquitas, con excepción de los pocos funcionarios y empleados públicos (...) Desde el punto de vista comercial, Coranzulí actúa como un centro concentrador de mercaderías. En efecto, hay tres comercios acopiadores con vehículos propios que compran lana a los pastores de la zona y la venden en Abra Pampa, en Salta y hasta en Tucumán" (1978:60). Esto nos permite inferir que había una mayor permanencia de las personas en el pueblo ${ }^{16}$, lo que estaría en línea con la trama urbana a partir de la densificación de las manzanas, aunque también permite pensar en la persistencia de esquemas de movilidad de distintas frecuencias. En síntesis, la creación de la Comisión Municipal en Coranzulí trajo aparejado ciertos cambios sustantivos: (1) en sus relaciones político-administrativas con otros centros urbanos de la provincia y con el propio poder político provincial y (2) en las actividades laborales de las personas y las dinámicas dentro del pueblo. La forma urbana da cuenta de estas transformaciones de modo articulado, en tanto lo constituye como un sitio de visibilidad estatal, con una forma urbana que puede ser decodificada dentro de las lógicas de sus agentes y, que, por lo tanto, posee una organización formal y simbólica diferente a la del campo. En este sentido, podemos avanzar sobre la actualidad para observar el modo en que esta lógica de ordenamiento cuya centralidad está dada por la presencia de la Comisión Municipal, entra en relación con la que hasta su creación poseía la iglesia como principal institución del pueblo.

En la actualidad, Coranzulí es un centro urbano que ha experimentado una significativa expansión en su tejido (Figura N07), a través de la cual se consolidó una forma urbana en damero dentro de la cual se distinguen, de un modo claro, edificios institucionales y espacios de uso público que evidencian la conformación efectiva de una forma urbana asociada a los intereses estatales.

16 Lamentablemente, no poseemos información específica para analizar en términos cuantitativos las dinámicas poblacionales de Coranzulí hasta recién el año 1991, por lo que no podemos saber de manera efectiva si ha habido un crecimiento poblacional en estos años. 
Figura No7

Reconstrucción de la progresión del crecimiento de la mancha urbana de Coranzulí a partir de los registros fotográficos históricos y el relevamiento actual

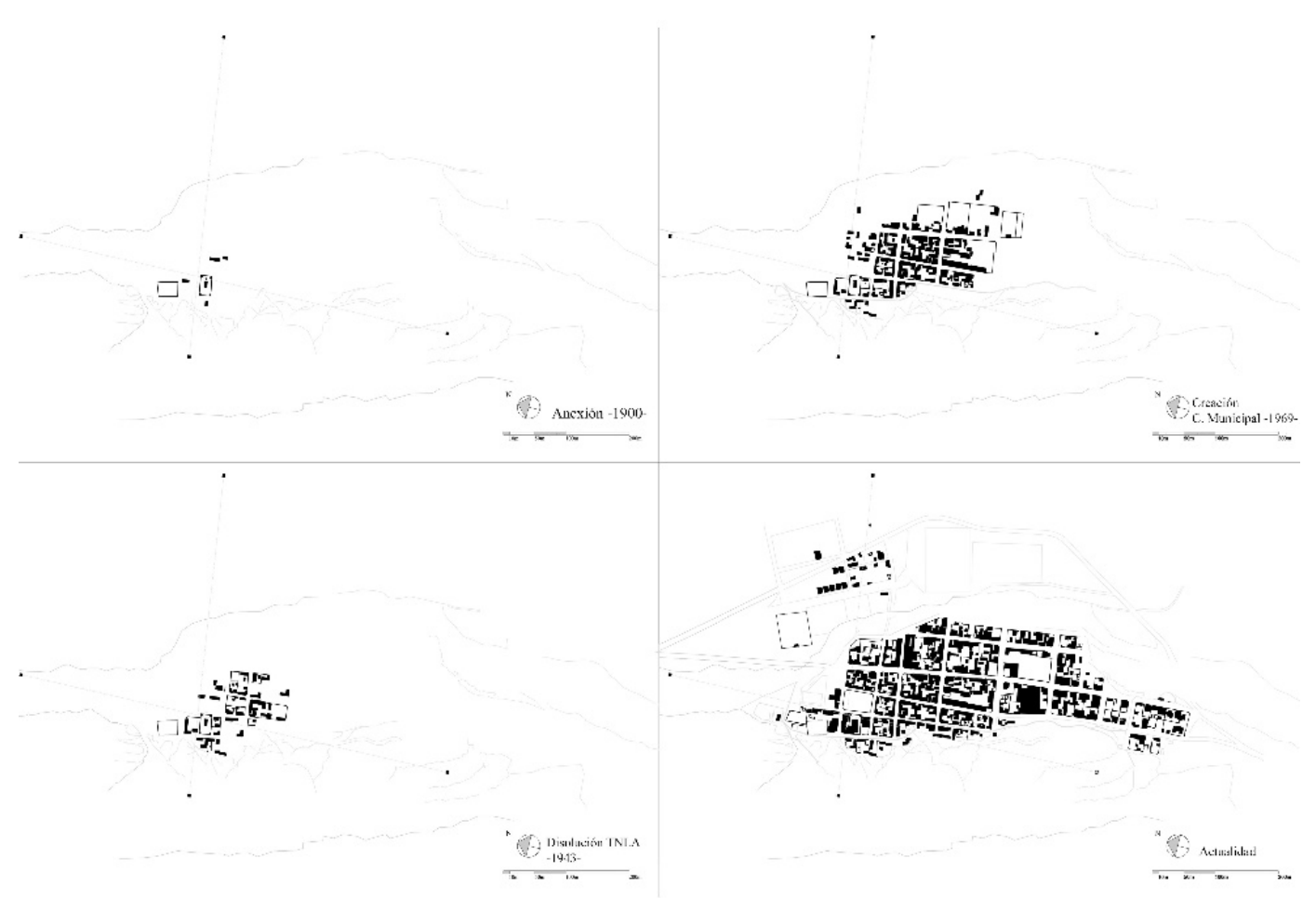

Fuente: elaboración propia.

Aunque el tejido no es regular en su extensión, pareciera predominar una dirección norte-sur, de acuerdo con los ejes del cauce del río y el constituido por la avenida principal, que se extiende de norte a sur del tejido urbano. En este sentido, es necesario señalar que en relación con dicho tejido, se destaca la presencia de cuatro calvarios que se localizan en los puntos cardinales, trazando un eje en forma de cruz con la posición de la capilla, como estructuras de marcación del límite del espacio del pueblo, tal como lo señalamos anteriormente (Figura No8). Sin embargo, la notable expansión hacia el sur experimentada por el tejido condujo a que este supere el límite establecido por el calvario localizado en dicho punto cardinal.

La expansión del tejido urbano hacia el sur se asocia, a su vez, con el desarrollo de un nuevo loteo, sobre el otro margen del río, en La Banda. Estos sectores presentan algunas cuestiones significativas en relación con la conformación de los terrenos y el rol que ocupa, en la actualidad, la figura del lote. La adjudicación de estos a las familias por parte de la Comisión Municipal se da de manera gratuita, pero su condición de propiedad continúa siendo fiscal, aun cuando el nombre del adjudicatario esté asentado en el catastro local. Las Resoluciones Municipales en las que se registra el otorgamiento de los lotes son cédulas pre elaboradas por la propia Comisión Municipal. Es interesante señalar el texto que forma parte de estas, donde se exponen algunas ideas centrales sobre los sentidos por los cuales funciona este esquema: "es menester de la Co- 
muna contemplar este tipo de peticiones por tratarse de lotes baldíos dentro del ejido Urbano del Pueblo, para de esta manera facilitar a los futuros Pobladores, contar con una vivienda, facilitando su arraigo en la zona, evitando de esa forma el despoblamiento en el que se encuentra sumida la Puna toda"17. A partir de este fragmento, podemos notar que este sistema de adjudicación de lotes en el pueblo se constituyó en función de la histórica voluntad del Estado de que los pastores se asienten en los pueblos. Sin embargo, este interés está operando aquí en un contexto diferente al planteado para el momento de la anexión y resulta significativo para pensar a los pueblos como lugares. El 'despoblamiento' al que refieren estas cédulas se encuentra asociado no sólo a la actividad pastoril en el campo sino también a la ausencia de la población asociada a los desplazamientos laborales implicados en la actividad minera o el trabajo asalariado, y también a aquellas dinámicas cotidianas como la compra de mercadería para el comercio o los viajes por la atención médica o bancaria.

Desde la década de 1990, fue posible encontrar una intensa actividad de entrega de lotes a distintas familias, de forma gratuita, por parte de este organismo, con destino en la construcción de casas particulares por parte de los pobladores. Se trata de un total de 33 pedidos registrados entre 1990 y 2013. A su vez, es importante que notemos que la intervención de la Comisión Municipal sobre los lotes y su destino no finaliza al momento de su entrega sino que cumple un rol en el control de la urbanización. La Comisión Municipal otorga un plazo de dos años luego de adjudicado el lote para que su adjudicatario construya su casa, y en caso contrario, este deberá ser restituido. De esta manera, se busca garantizar la continuidad constructiva del tejido urbano, evitando que queden lotes vacíos en las manzanas consolidadas. Asimismo, en las últimas décadas se incorporó una cuarta alternativa en la producción de terrenos y casas en el pueblo. No es la adjudicación de un lote para la construcción particular sino que, en este caso, es la acción integral del Estado en la producción de vivienda. Son las propias agencias estatales las que, entonces, definen los lotes y sus construcciones, las que una vez culminadas son, sí, adjudicadas a los pobladores a través de un proceso que es, también, regulado por el propio Estado (Barada, 2018b). De hecho, el nuevo loteo de La Banda comenzó a densificarse a partir de la producción de un plan de cinco viviendas construido en 2012 , el segundo del pueblo ${ }^{18}$. Sin embargo, este tejido no encuentra continuidad con el resto del pueblo sino que se localiza hacia el este, sobre el otro margen del Río Coranzulí. Se encuentra escasamente construido y en él no logran distinguirse de un modo claro manzanas y calles (Figura No8).

Fragmento de la Cédula Oficial de pedido y entrega de lotes, Comisión Municipal de Coranzulí. Ejemplo tomado de la Resolución Municipal № 012, del año 1995.

18 Un primer plan de cuatro viviendas se localiza en el extremo sur del tejido urbano, y fue realizado en la década de 1990, en el marco de la expansión urbana que experimentó en pueblo hacia el sur. 
Figura No8

Plano actual del pueblo de Coranzulí, indicando la localización de las instituciones cívicas y eje definido por la avenida, así como el centro históricamente conformado por la Iglesia

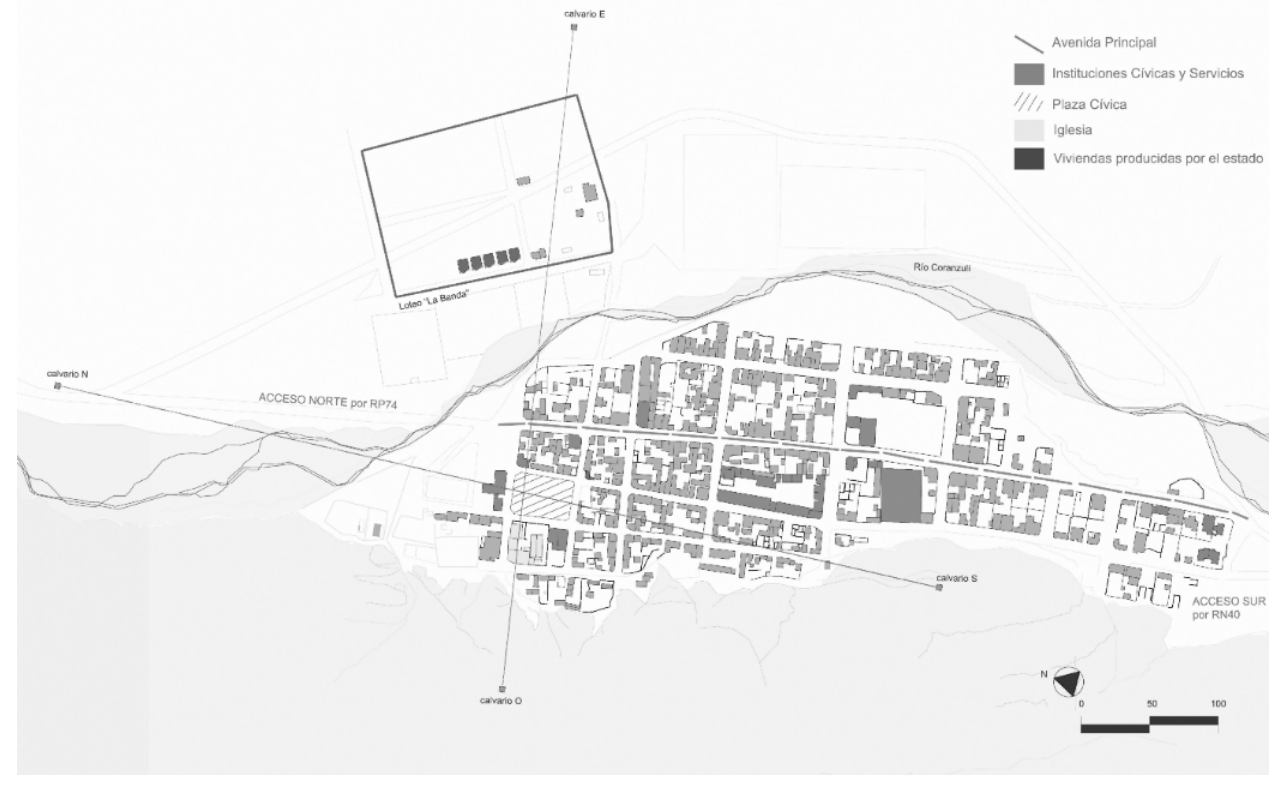

Fuente: elaboración propia.

En síntesis, la actualidad de la forma urbana de Coranzulí plantea una serie de diferencias respecto de los momentos anteriores: (1) El crecimiento del tejido implicó el establecimiento de límites precisos sobre los bordes del pueblo, anulando la presencia de rastrojos o corrales que sí podían verse hasta la fotografía de 1970. Por otra parte, la expansión del tejido hacia el sur y la construcción del loteo de La Banda, dan cuenta de un contundente crecimiento en la cantidad de casas presentes allí, lo que nos permitiría pensar, sólo en principio, en una mayor cantidad de familias residiendo en el pueblo. (2) Este tejido residencial ya no es únicamente producto de la acción individual de las familias sino que evidencia la acción directa del Estado en a través de la introducción de las viviendas. (3) La distinción entre los edificios institucionales y los domésticos que se mostró de manera incipiente en el momento de conformación de Coranzulí como Comisión Municipal se concretiza en la forma urbana actual, se observan diferentes escalas y morfologías en su construcción. Esto es relevante en función notar la introducción de otras tipologías edilicias, cuyas características morfológicas y funcionales se deben a la incorporación de instituciones, servicios, espacios de sociabilidad propios de la consolidación de un centro urbano y administrativo. En este contexto, la conformación urbana de la plaza en el sector norte del poblado -hasta entonces definida a partir del espacio abierto frente a la iglesia-, se constituye como una de las operaciones más significativas. Así, la centralidad de la iglesia se ve atravesada por, lo que podemos llamar, un doble desplazamiento. Por un lado, condición de centro geográfico del poblado fue desplazada a partir del crecimiento hacia el sur, a la vez que en términos sociales y simbólicos, disputa su relevancia con el desarrollo de la avenida, sobre la que se localizan la mayor parte de las instituciones estatales y los comercios. Por el otro, la inserción de la plaza cívica y una serie de estructuras asociadas a esta, tales como los baños públicos, la terminal de ómnibus y 
el centro vecinal, contribuyen a que aquel centro ceremonial asociado a la iglesia y su atrio que se observaba en la primera fotografía de Cerri, se vea redefinido en función de otros usos y sentidos que, lejos de comprenderse de un modo aislado, operan de un modo simultáneo (Figura No9).

Figura No9

Redefinición de la centralidad de la iglesia en relación con la forma urbana del pueblo.
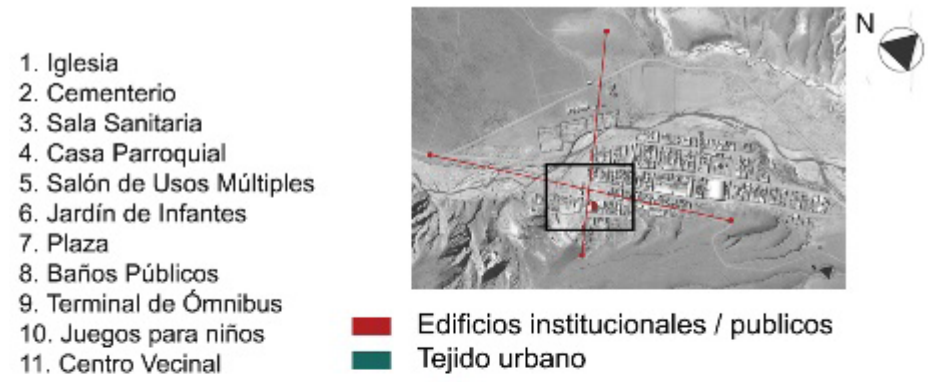

Edificios institucionales / publicos

Tejido urbano

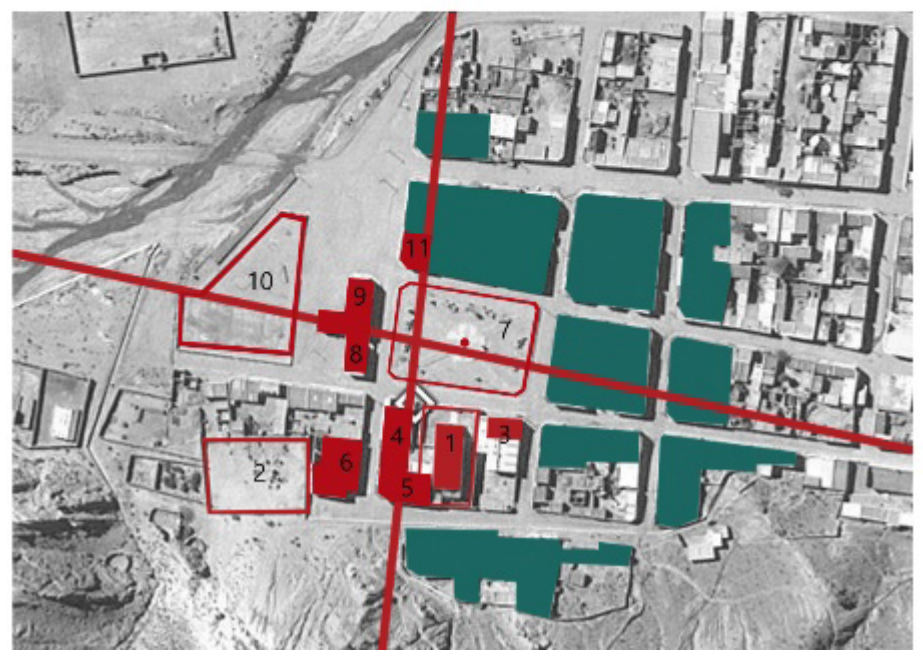

Fuente: elaboración propia sobre base de imagen satelital.

Podemos problematizar estas transformaciones, y particularmente la expansión del tejido urbano, a la luz de los relevamientos poblacionales de las últimas décadas en el Cuadro N²:

\section{Cuadro $\mathrm{N}^{\circ} 2$}

Información poblacional de relevamientos realizados entre la década de 1970 y la actualidad

\begin{tabular}{|c|c|c|c|l|}
\hline \multirow{2}{*}{ AÑos } & \multicolumn{3}{|c|}{ Población * } & \multirow{2}{*}{ FUENTES } \\
\cline { 2 - 5 } & $\begin{array}{c}\text { Total } \\
\text { Provincia }\end{array}$ & $\begin{array}{c}\text { Departamento } \\
\text { de Susques }\end{array}$ & Coranzulí & \multicolumn{1}{|c|}{ FU } \\
\hline 1970 & 302476 & 1826 & - & $\begin{array}{l}\text { *Censo Nacional de Población y Vivienda } 1970 . \\
\text { INDEC. }\end{array}$ \\
\hline 1980 & 410188 & 2184 & - & $\begin{array}{l}\text { *Censo Nacional de Población y Vivienda } 1980 . \\
\text { INDEC. }\end{array}$ \\
\hline
\end{tabular}




\begin{tabular}{|c|c|c|c|c|}
\hline \multirow[b]{2}{*}{ AÑos } & \multicolumn{3}{|c|}{ Población * } & \multirow[b]{2}{*}{ FUENTES } \\
\hline & \begin{tabular}{|c|} 
Total \\
Provincia
\end{tabular} & $\begin{array}{c}\text { Departamento } \\
\text { de Susques }\end{array}$ & Coranzulí & \\
\hline 1991 & 512329 & 2846 & 324 & $\begin{array}{l}\text { *Censo Nacional de Población y Vivienda } 1991 . \\
\text { INDEC. }\end{array}$ \\
\hline 1997 & - & - & - & $\begin{array}{l}\text { ** Programa Nacional Mapa Educativo. http// } \\
\text { www.mapaeducativo.edu.ar }\end{array}$ \\
\hline \multirow{2}{*}{2001} & 611888 & 2854 & 412 & $\begin{array}{l}\text { *Censo Nacional de Población y Vivienda } 2001 . \\
\text { INDEC. Procesado con Redatam }\end{array}$ \\
\hline & - & - & 548 & $\begin{array}{l}\text { Censo realizado por los agentes de Atención Pri- } \\
\text { maria de la Salud (APS) en Coranzulí. }\end{array}$ \\
\hline 2002 & - & - & 559 & $\begin{array}{l}\text { Censo realizado por los agentes de Atención Pri- } \\
\text { maria de la Salud (APS) en Coranzulí. }\end{array}$ \\
\hline 2003 & - & - & 566 & $\begin{array}{l}\text { Censo realizado por los agentes de Atención Pri- } \\
\text { maria de la Salud (APS) en Coranzulí. }\end{array}$ \\
\hline 2004 & - & - & 557 & $\begin{array}{l}\text { Censo realizado por los agentes de Atención Pri- } \\
\text { maria de la Salud (APS) en Coranzulí. }\end{array}$ \\
\hline 2005 & - & - & 555 & $\begin{array}{l}\text { Censo realizado por los agentes de Atención Pri- } \\
\text { maria de la Salud (APS) en Coranzulí. }\end{array}$ \\
\hline 2010 & 673307 & 3791 & 333 & $\begin{array}{l}\text { *Censo Nacional de Población, Hogares y Vivien- } \\
\text { da } 2010 \text { / Procesado con Redatam+SP, CEPAL/ } \\
\text { CELADE. INDEC. }\end{array}$ \\
\hline 2014 & - & - & 339 & $\begin{array}{l}\text { Censo realizado por los agentes de Atención Pri- } \\
\text { maria de la Salud (APS) en Coranzulí. }\end{array}$ \\
\hline
\end{tabular}

Fuente: elaboración propia a partir de las fuentes citadas.

Entre la década de 1990 y hasta el año 2010, podemos observar un pequeño incremento poblacional, correspondiente con los procesos de crisis del sector minero en los cuales parte de la población que se encontraba residiendo en centros laborales regresó al pueblo. Esto se corresponde con el incremento de pedidos de lotes observado en las Cédulas de la Comisión Municipal. A partir de estos años, es que podemos pensar en la mayor actividad constructiva en el pueblo, la densificación de las manzanas y finalmente la concreción de la expansión al sur y del loteo en La Banda, en articulación con las viviendas producidas por el Estado. Sin embargo, a partir del segundo decenio de la década del 2000, mientras que los loteos y las viviendas continuaron proyectándose, la población experimentó un nuevo descenso. Este último, se corresponde con el incremento poblacional que se observa en Susques, como producto de las migraciones que se dieron en el marco de la apertura del Paso de Jama y la instalación de sus infraestructuras de servicios, que dieron lugar a un nuevo campo de alternativas laborales para la población del área (Tomasi y Benedetti, 2003). En relación a este último dato, comprender la continuidad de las nuevas construcciones en el marco de un descenso poblacional, permite posicionar las acciones locales sobre la forma urbana del pueblo como estrategias a ser atendidas en el marco de una negociación. A continuación avanzaremos sobre estas ideas. 


\section{Discusión. Las ideas sobre el "orden" y el "desorden"}

Como ha planteado Oszlak (2012) "orden y progreso" se constituyeron como los pilares centrales del proceso de formación del Estado Argentino. Mientras que la noción de orden implicaba regular el funcionamiento de la sociedad y normalizar sus comportamientos, su asociación con la idea del progreso -impulsada por las elites liberales- conllevaba a que, para lograr dicha regularización, "el orden aparecía entonces como una drástica modificación del marco habitual de las relaciones sociales" (Oszlak, 2012:28). Para la población de la Puna de Atacama, la inserción al Estado Argentino fue su definitiva incorporación a un aparato institucional que hasta entonces -durante su pertenencia a Bolivia y a Chile- no había estado presente de manera directa y que estaba encabezado por la escuela y por los dispositivos administrativos de registro, control y clasificación de la población. Es a partir de estos dispositivos que se persiguió institucionalizar, normalizar y regular las relaciones sociales. Como ha planteado Segato, "El papel del Estado Argentino y sus agencias, particularmente la escuela, la salud pública y el servicio militar obligatorio e ineludible, fue el de una verdadera máquina de aplanar diferencias de extrema e insuperable eficiencia" (2002:17). Sin embargo, transformar los "marcos habituales de las relaciones sociales" en los términos de Oszlak (2012) requiere, necesariamente, transformar sus espacios. Particularmente en la Puna, un ámbito que por sus características geográficas, sociales y productivas, había resultado ajeno para el Estado, las primeras acciones desplegadas a comienzos del siglo XX estuvieron asociadas al establecimiento de un orden material que posibilitó la transformación de su espacio para pasar a ser una parte reconocible y clasificable en la totalidad nacional.

Si bien en la Argentina las políticas urbanísticas estuvieron enfocadas a la transformación de las grandes ciudades y capitales provinciales, Coranzulí, así como también los restantes poblados del TNLA no han quedado exentos de su incidencia. La condición de territorio nacional que tuvo este sector del área puneña hasta casi la mitad del siglo XX, resulta significativa para pensar el alcance de estas ideas, ya que se trató de un espacio cuyas políticas institucionales fueron dirigidas de un modo directo desde el Poder Ejecutivo Nacional, prácticamente hasta mediados del siglo XX. En este contexto, lejos de ser reconocido desde la órbita estatal como un ámbito social y materialmente definido a partir de las lógicas de asentamiento y organización colectiva de las familias de pastores en el campo, el espacio puneño fue decodificado como un ambiente desértico, hostil y deshabitado (Holmberg, 1990; Cerri, 1993 [1903]; Boman, 1908; entre otros). Así, aquellos sitios que los primeros viajeros clasificaron como "caseríos", fueron comprendidos como lugares caóticos y desordenados sobre los que el Estado debía intervenir. Podemos retomar la citada descripción de Holmberg (1900) sobre los principales caseríos en el TNLA, dando cuenta de que se trataba de "ranchos" y "capillas" que han sido edificados de manera conjunta, denotando que no existía allí ningún otro edificio institucional. Además, sugirió que estas "reuniones de familias" eran un "amontonamiento desordenado de ranchos" descartando la posibilidad que su conjunto con la capilla posea algún tipo de intencionalidad. De acuerdo con su observación, no se les atribuía ninguna voluntad proyectual a los constructores de los "ranchos". Por el contrario, su construcción y características fueron consideradas como el resultado inevitable de una topografía complicada. Es en este tipo de lecturas que la relevancia de la capilla como centro, y en particular de los calvarios como estructuras que definen los límites entre el campo y el pueblo significándolos mutuamente, ha sido invisibilizada. 
Aun en este contexto, cuando retomamos el devenir de la forma urbana de Coranzulí, podemos observar que su ordenamiento tuvo un desarrollo en la clave planteada por el Estado, aun cuando su población no haya establecido residencia fija en él -incluso las variaciones se observan en el descenso poblacional de los últimos veinte años- y aun cuando no hayamos encontrado en los documentos escritos ninguna referencia a la existencia de ordenanzas específicas ${ }^{19}$. Las agencias locales han tenido un papel activo en este proceso. Muy probablemente, estas ideas hayan ingresado a través otros centros urbanos, pueblos con los que Coranzulí mantenía un activo canal de comunicación, más allá de la acción de las autoridades del Territorio de Los Andes y de los posteriores gobiernos provinciales que han intervenido en la construcción formal de Coranzulí. En otras palabras, estas han sido aprehendidas localmente en el marco de las propias dinámicas y relaciones de la población local, las que, las más de las veces, escapaban a los circuitos y vías de comunicación oficiales. En este contexto, debemos considerar el rol central que ocuparon instituciones como el Centro Vecinal y la autoridad del Capitán ${ }^{20}$ en la mediación entre los intereses estatales y las acciones locales en el pueblo. Lo propio ocurre cuando pensamos en el rol que ha tenido, particularmente desde la conformación de Coranzulí como Comisión Municipal, el empleo minero y posteriormente estatal en la movilidad de las personas y las familias a otros centros urbanos. Los centros mineros han sido, en definitiva, sitios propicios para el intercambio de ideas y bienes entre personas que provenían de distintos lugares. Sin embargo, ¿se trata simplemente de una reproducción de la lógica estatal desde la "periferia", o debemos considerar la acción local como instancia de negociación entre los intereses locales y estatales?

Hasta la creación de la Comisión Municipal no se establecieron normativas locales que operasen de un modo directo sobre el desarrollo de la forma urbana de Coranzulí. Sin embargo, fuimos observando un crecimiento sostenido de las construcciones en el pueblo incluso cuando al menos hasta la primera mitad del siglo XX la población no residiese de modo permanente allí. Sin embargo, la forma urbana de este ya podía ser decodificada en la clave propuesta por el Estado, aun cuando esta coexistiese -como de hecho lo hace hasta el día de hoy-, con otras formas de ordenamiento como es la de la iglesia como centro y los calvarios como límites. Asimismo, la progresiva separación entre espacios públicos y parcelados tensionó las lógicas locales de continuidad constructiva asociadas a los domicilios en el campo, con la de los lotes pre-fijados, regulados por una entidad pública. Luego, la introducción de la Comisión Municipal definió un esquema de regulaciones que también, fue, en cierto modo, moldeado por las lógicas locales ante un crecimiento sostenido de las construcciones a través de la solicitud de lotes fiscales e incluso de viviendas producidas directamente por el Estado. Sin embargo, esto se dio en un escenario en el que la movilidad persiste como práctica habitual de las familias locales, aun cuando muchas de estas estén mediadas en la actualidad por otras lógicas asociadas, incluso, a las imposiciones del mismo Estado: el trabajo asalariado, el ingreso a un sistema de salud, un sistema bancario, etc. En efecto, el resultado de estos procesos ha sido valorado, en buena medida, por estudios posteriores realizados desde el plano académico y también estatal. Una de las descripciones de

\footnotetext{
Encontramos en los Libros Copiadores del Territorio Nacional de Los Andes, ordenanzas particulares sobre la localización de prostíbulos, y sobre la construcción en los lotes urbanos en el pueblo de San Antonio de Los Cobres pero no para los restantes poblados del territorio. Sí existen algunas especificaciones generales para la obra pública y los materiales de construcción en general a las que nos referiremos en la Segunda Parte del Capítulo.

20 El capitán era el cargo más alto ejercido por autoridades indígenas en los centros poblacionales de la Puna. Su rol era relevante en la mediación de las disputas internas, pero especialmente como interlocutor hacia 'el afuera' (Tomasi, 2011).
} 
Coranzulí que aparece en el libro de Geografía de Jujuy realizado en 1960, resulta contundente en este sentido: “Coranzulí (...) es un pueblito bien trazado, con calles rectas; cuenta con una iglesia de construcción no muy antigua, Escuela Nacional, edificio para oficinas públicas y dos o tres casas de comercio. Hasta la localidad de Coranzulí se puede llegar en automóvil por un camino muy accidentado y bien construido" (Geografía de Jujuy, 1960).

¿Se trata, entonces, de un 'triunfo' de aquellas ideas del 'orden' estatal o es más bien la expresión de un lugar que se define a través de relaciones internas y externas mediadas, practicadas, finalmente controladas, en buena medida, por los actores locales?

\section{Reflexiones finales: los 'centros poblados' y los 'pueblos vacíos'}

El objetivo de este artículo fue evidenciar la interacción entre las acciones estatales y las agencias locales en la construcción de la forma urbana de Coranzulí a lo largo del siglo XX. Como vimos a lo largo del tiempo, la relación entre la población que residía en el pueblo y desarrollo del tejido urbano no ha sido lineal, lo que resultó central para el problema planteado. A partir de esta cuestión podemos problematizar el rol que ha tenido la forma urbana en la construcción del pueblo como lugar, intentando distinguir, en particular, el papel que han tenido las agencias locales.

\section{Los centros poblados}

Hemos notado que las nociones sobre el orden que expresa la forma urbana actual de Coranzulí forman parte de aquellas ideas producidas desde comienzos del siglo XX en el marco de la conformación del territorio argentino, evidenciando sus efectos incluso en aquellos espacios sobre los que -como Coranzulí-, no se produjeron, en general, ordenanzas concretas y se encontraban alejados geográfica, política y económicamente de los centros de poder. Desde esta perspectiva, comprender cómo un sitio que se anexó a la Argentina recién en el siglo XX y cuya población no vivía allí, en sólo cuarenta años poseía ya un número considerable de casas ordenadas en manzanas y para 1970, una forma urbana dentro de la cual ha sido posible reconocer la distinción entre espacios públicos y privados, implicó asumir que, aun en un contexto de imposiciones, hubo una intención explícita de la población local por hacer de Coranzulí un lugar en clave estatal desde el cual es posible para la población local disputar los propios sentidos del pueblo ante el Estado. Así, las relaciones que Coranzulí ha tenido con otros espacios urbanos a través de las relaciones sociales y políticas de su población, son absolutamente significativas para proponer la hipótesis de cómo la idea del orden y la imagen urbana que se construyó en otros sitios del territorio, repercutieron en el devenir del propio pueblo a través de la construcción de intereses y sentidos 'estatales' en la población local. Hacia las últimas décadas del siglo XX, las relaciones que atravesaron la actividad minera como práctica laboral, el comercio y el empleo estatal son algunos de los factores que deben ser considerados a la hora de pensar en los ordenamientos presentes en Coranzulí, sus espacios públicos y edificaciones, y el modo en el que el orden 'urbano' asociado a las ideas promovidas desde el Estado se hizo presente en la forma urbana del pueblo. Finalmente, es posible definir a Coranzulí como un centro poblado en clave estatal, aun cuando su existencia no se corresponda, necesariamente, con la de un "centro poblado". 


\section{Los pueblos 'vacíos'}

Si partimos por el contrario, de considerar el pueblo como lugar de lo pastoril, debemos recordar qué aun en este contexto, expusimos algunas ideas -en principio, contrapuestas-, sobre la regulación estatal y las agencias locales en el desarrollo de los lotes y manzanas, y en particular, de sus límites. Sus expresiones en la forma urbana no pueden concebirse de un modo sucesivo y escindido a lo largo del tiempo, sino que se trata más bien de construcciones dinámicas que continúan actuando de modo entreverado. En este sentido, no podemos dejar de observar la tensión que existe entre este ordenamiento y el que proponen los calvarios, la iglesia y el atrio, como materialidades que, en clave local, dan cuenta del rol que el pueblo posee como lugar para la espacialidad pastoril, aun cuando este sólo haya sido habitado en momentos puntuales del año. Si considerásemos al lugar en la línea planteada por Tuan (1996 [1974]), se podría pensar que, aun cuando el pueblo haya sido un sitio mayormente deshabitado, su sentido para la cohesión de las familias operó en su conformación como lugar en esta clave, incluso cuando la forma urbana del pueblo haya ido desarrollando características formales que pueden ser comprendidas en la clave estatal. Sin embargo, estos ordenamientos no pueden ser considerados de un modo aislado, cuando, de hecho, son los propios calvarios como límites los que se ponen en tensión ante el crecimiento del tejido urbano hacia el sur.

Podemos recuperar, entonces, la idea de lugar planteada por Massey (2004), para considerar a las diferentes tramas que finalmente se superponen y se entrelazan en Coranzulí, como materialidades que se construyen en la especificidad del pueblo a través de las que se operan relaciones más amplias. $Y$ es justamente en desde esta especificidad del lugar, que no puede diferenciarse de modo taxativo entre "intereses estatales" e "intereses locales" sino que, muy por el contrario, debemos pensar que se trata de agencias, intereses, ideas, acciones, que operaron y operan de un modo entreverado en la definición de la forma urbana del pueblo. En otras palabras, Coranzulí es un lugar que es parte de una única espacialidad que se constituye en articulación con el campo y es simultáneamente un pueblo que puede ser comprendido como un nodo en una red de poblados que, en clave estatal, se desarrollaron en la Puna y que trasformaron aquel espacio "vacío" en un lugar comprensible en la clave espacial y material del Estado. Podemos preguntarnos acerca del rol que posee la materialidad, en este caso constituida a través de las dinámicas de producción, pasadas y actuales, de la forma urbana del pueblo, en la definición de este como lugar, en un contexto en que las tensiones entre la sedentarización y la movilidad vuelven a hacerse presentes. Coranzulí es un centro poblado que sigue creciendo y construye nuevos proyectos urbanos en su desarrollo a través de loteos que, promovidos desde las agencias estatales, son actuados desde las agencias locales en un contexto geográfico adverso que había sido, en principio, determinante de su "falta de proyección".

\section{Referencias bibliográficas}

ABELEDO, S. Los Pastores de la Altura. Una mirada evolutiva de la vida en la Puna de Atacama, Tesis de licenciatura en Ciencias Antropológicas. Buenos Aires: Facultad de Filosofía y Letras, Universidad de Buenos Aires, 2008, Inédita.

ABERCROMBIE, T. Caminos de la memoria y del poder. Etnografía e historia en una comunidad andina. La Paz: Instituto de Estudios Bolivianos e Instituto Francés de Estudios Andinos, 2006 [1998]. 
ACADEMIA NACIONAL DE BELLAS ARTES. Documentos de Arte Argentino. Cuaderno Ilbis "Ramificaciones del Camino de la Quebrada de Humahuaca y del Camino de los Incas". Buenos Aires: ANBA, 1942.

ALBÓ, J. Nación de muchas naciones: nuevas corrientes políticas en Bolivia. En: GONZÁLEZ CASANOVA, P. (ed.) Democracia y estado pluriétnico en América Latina. México: Centro de Investigaciones Interdisciplinarias en Ciencias y Humanidades, UNAM, 1996, p. 321-366.

ALLEN, C. J. La coca sabe: coca e identidad cultural en una comunidad andina. Cusco: Centro de Estudios Regionales Andinos Bartolomé de las Casas, 2008 [2002].

BAIGORRI, A. De lo rural a lo urbano. Hipótesis sobre las dificultades de mantener la separación epistemológica entre Sociología Rural y Sociología Urbana en el marco del actual proceso de urbanización global, V Congreso Español de Sociología, 1995.

BARADA, J. Entre el patrimonio y la historia. Transformaciones arquitectónicas en una iglesia puneña ante las lógicas estatales en el siglo XX (Coranzulí, Jujuy, Argentina). Revista del Museo de Antropología, UNC, 2018a, 11(1), p. 183-194.

BARADA, J. Entre casas, departamentos y viviendas. Una etnografía de las relaciones entre los pastores y el Estado desde la producción de arquitectura doméstica en un pueblo puneño. Buenos Aires: Antropofagia, Serie Eduardo Archetti, 2018b.

BARADA, J. Un pueblo es un lugar. Materialidades y movilidades de los pastores andinos ante las lógicas del Estado (Coranzulí, Jujuy, Argentina). Tesis de doctorado en Geografía. Buenos Aires: Facultad de Filosofía y Letras, Universidad de Buenos Aires, 2017, Inédita.

BARROS, C. Reflexiones sobre la relación entre lugar y comunidad. Documents d' Análisi Geografica, 2000, N 37, p. 81-94.

BENEDETTI, A. Un territorio andino para un país pampeano. Geografía histórica del Territorio de Los Andes (1900-1943). Tesis doctoral en Geografía. Buenos Aires: Facultad de Filosofía y Letras, Universidad Buenos Aires, 2005, Inédita.

BOLSI, A. y R. GUTIÉRREZ Susques. Notas sobre la evolución de un pueblo puneño, Documentos de Arquitectura Nacional No 2, 1974, p. 14-29.

BOMAN, E. Antigüedades de la región andina de la República Argentina y del desierto de Atacama, Tomo I y II. San Salvador de Jujuy: Universidad Nacional de Jujuy, 1991 [1908].

CASTRO, H. Otras miradas, otros lugares. Los relatos de viajeros en la construcción de la Puna argentina. En: ZUSMAN, P., LOIS, C., CASTRO, H. (eds.). Viajes y geografías. Exploraciones, turismo y migraciones en la construcción de lugares. Buenos Aires: Prometeo, 2007, p. 93-113.

CAPEL, H. La definición de lo urbano. Estudios Geográficos, 1977, № 138-139. p. 265-301. 
CERRI, D. El territorio de los Andes. Reseña Geográfica Descriptiva por su primer gobernador el Gral. Daniel Cerri. Jujuy: UNJU, 1993 [1903].

DELFINO, D. Las pircas y los límites de una sociedad. Etnoarqueología en la Puna (Laguna Blanca, Catamarca, Argentina). En: KUZNAR, L. (eds.) Ethnoarchaeology of Andean South America. Michigan: International Monographs in Prehistory, Ethnoarchaeological Series 4, 2001, p. 97-137.

DELGADO, F. El Territorio Nacional de Los Andes. Creación, límites, objetivos económicos del Estado nacional, reacciones de sus actores sociales y problemática por la tenencia de 1900-1905. Ponencia presentada en Jornadas Interescuelas de Departamentos de Historia, Córdoba, 2003.

FABERMAN, J. y R. BOIXADÓS Sociedades indígenas y encomienda en el Tucumán colonial. Un análisis comparado de la visita de Luján de Vargas. Revista de Indias, 2006, vol. LXVI, № 238, p. 601-628.

GALDAMES, L., CHOQUE MARIÑO, C. y A. DÍAZ ARAYA. De apachetas a cruces de mayo: identidades, territorialidad y memorias en los altos de Arica, Chile. Intericiencia, 2016, Vol.41, No8, p. 526-532.

GISBERT, T. y J. MESA Arquitectura Andina. Historia y análisis. La Paz: Colección Arzans y Vela, Embajada de España en Bolivia, 1985.

GÖBEL, B. La arquitectura del pastoreo: Uso del espacio y sistema de asentamientos en la Puna de Atacama (Susques). Estudios Atacameños, 2002, No 23, p. 53-76.

HIDALGO, J. Incidencias de los patrones de poblamiento en los cálculos de la población del Partido de Atacama desde 1752 a 1804. Las revistas inéditas de 1787-92 y 1804. Estudios Atacameños, 1978, N6, 49-105.

HIERNAUX, D. y A. Liendón Geografía urbana: una mirada desde América Latina En Bertrand G y D. Hiernaux Tratado de Geografía Humana. Barcelona: Anthropos Editorial, 2006.

HOLMBERG, E. (h.). Viaje por la Gobernación de Los Andes (Puna de Atacama). Buenos Aires: Ministerio de Agricultura de la República Argentina, Dirección de Agricultura y Ganadería. "La Nación", 1900.

KHAZANOV, F. Nomads and the outside world. Wisconsin: The University of Wisconsin Press, 1994.

LATOUR, B. Reensamblar lo social. Una introducción a la teoría del actor-red. Buenos Aires: Manantial, 1998.

MARTíNEZ, J.L. Adaptación y Cambio en los Atacameños. Los indios en el período colonial. Siglos XVI y XVII. Andes, 1985, No3, p. 9-25. 
MARTINEZ, J.L. La formación del actual pueblo de Toconce (siglo XIX), Revista Chungara, N015, 1985, p. 99-124.

MASSEY, D. Lugar, identidad y geografías de la responsabilidad en un mundo en proceso de globalización. Treballs de la Societat Catalana de Geografia, Núm. 57, 2004, p. 77-84.

MASSEY, D. (ed.) Space, Place and Gender. Minneapolis: University of Minnesota Press, 1994.

MERLINO, R. y M. RABEY El ciclo agrario-ritual en la puna argentina, Relaciones de la Sociedad Argentina de Antropología, Vol XII, 1978, p. 47-70.

MILLER, D. (ed.) Materiality. Durham: Duke University Press, 2005.

MOLINA OTAROLA, R. Relaciones transfronterizas entre atacameños y collas en la frontera norte chilena-argentina. La Desintegración de Espacios y Articulaciones Tradicionales Indígenas. En: Institut de recherche et débat sur la gouvernance, 2008. Disponible en Internet: http://www.institut-gouvernance.org/fr/analyse/fiche-analyse-408.html

NIELSEN, A. Las chullpas son ancestros: paisaje y memoria en el altiplano sur andino (Potosí, Bolivia). En: ALBECK, C. et al. El Hábitat Prehispánico. Arqueología de la Arquitectura y de la Construcción del Espacio Organizado. San Salvador de Jujuy: EdiUnJu, 2010, p. 329-349.

NIELSEN, A. Competencia Territorial y Riqueza Pastoril en una Comunidad del Sur de los Andes Centrales (Dto. Potosí, Bolivia). Zooarqueología de Camélidos, 2, 1996.

NOGUERA, J. Elementos para una ordenación urbana. Barcelona: Editorial UPC., 1981.

OSZLAK, O. La formación del Estado Argentino. Orden, progreso y organización nacional. Buenos Aires: Ariel, 2012 [1982].

SANTOS, M. A Naturaleza do Espaço. San Pablo: Editora da Universidade de São Paulo, 2006.

SALZMAN, P. (Ed.) When nomads settle. New York: Praeger Publishers, 1980.

SANHUEZA TOHÁ, C. Las poblaciones de la puna de Atacama y su relación con los Estados Nacionales. Una lectura desde el archivo. En: Revista de Historia Indígena, 2001, № 5. p. 55-82.

SANHUEZA TOHÁ, C. Indios" de los oasis, "indios" de la puna. Procesos migratorios y rearticulaciones identitarias en atacama (susques, siglos XVIII-XIX). Chungara, Revista de Antropología Chilena, 2008, Vol. 40, №2. p. 203-217.

SVAMPA, M. El dilema argentino: civilización o Barbarie, Buenos Aires: Taurus, 2006 [1994]. 
TOMASI, J. Geografías del pastoreo. Territorios, movilidades y espacio doméstico en Susques (provincia de Jujuy). Tesis de doctorado en Geografía. Buenos Aires: Facultad de Filosofía y Letras, Universidad de Buenos Aires, 2011, Inédita.

TOMASI, J. Materialidades urbanas en tensión. El pueblo de susques desde comienzos del siglo XX. Anales del IAA, 2012, No42, p. 121-138.

TOMASI, J. "Una expresión del atraso" La arquitectura de la Puna de Atacama en las descripciones de viajeros, científicos y funcionarios a comienzos del siglo XX". Estudios Sociales del NOA. Nueva Serie, 2015, N015. p. 83-112.

TOMASI, J. y BENEDETTI, A. Territorialidades multiescalares. El Paso de Jama y el eje de capricornio, vistos desde un pueblo de pastores puneños (Susques, Jujuy, Argentina) En: NAVARRO FLORIA, P. y DELRIO, W. Araucanía-Norpatagonia. Cultura y espacio. San Carlos de Bariloche: Universidad Nacional de Río Negro, 2013; p. 14-32.

TUAN, Y-F. Space and Place: Humanistic Perspective. En: AGNEW, J., LIVINGSTNE, D. y A. ROGERS (eds.) Human Geography. An Essential Anthology. Oxford: Oxford university Press, 1996 [1974].

TURNER, M. Pastoralism. En: Gregory, D. et al. The dictionary of Human Geography. Oxford: Wiley-Blackwell, 2009, p. 521-522.

VITRI, C. Apachetas y mojones, marcadores espaciales del paisaje prehispánico. Revista 1 Escuela de Historia, 2002, Año 1, Vol.1, No 1. p. 179-191.

YACOBACCIO, H., MADERO, C. y M. MALMIERCA Etnoarqueología de pastores surandinos. Buenos Aires: Grupo de Zooarqueología de Camélidos, 1998.

\section{Fuentes Consultadas}

Archivo General de La Nación, Serie Histórica III. Libros copiadores del Territorio Nacional de Los Andes.

Archivo General de La Nación. Departamento de Documentos Fotográficos.

Centro de Documentación de Arquitectura Latinoamericana (CEDODAL). Archivo fotográfico y de postales históricas de la provincia de Jujuy.

Escuela Primaria N0362 “Héroes de Malvinas" de Coranzulí. Libro Histórico de la Escuela.

Comisión Municipal de Coranzulí. Documentos y ordenanzas (1970-2014). 
Territorios Nacionales. Dirección General de Territorios Nacionales. (1914). Censo de población de los Territorios Nacionales 1912, Imp. Guillermo Kraft.

Territorios Nacionales. Ministerio del Interior, Asesoría Letrada de Territorios Nacionales, Censo General de los Territorios Nacionales, República Argentina (1920). Tomo I, Establecimiento Gráfico A. de Martino, Buenos Aires, 1923.

Censos Nacionales de Población y Vivienda. Años: 1914, 1947, 1960, 1970, 1980, 1991, 2001 y 2010. INDEC, Buenos Aires.

Cédulas de rondas anuales de Atención Primaria a la Salud, Coranzulí. Años: de 2001 a 2014. 
